\title{
THE ORIGIN OF LUNG CYSTS IN CHILDHOOD
}

\author{
BY \\ D. J. CONWAY \\ From the Children's Department, University College Hospital, London
}

(Received for Publication October 15, 1950)

Since the early description of a lung cyst by Fontanus in 1638, many authors have thought these cases worthy of record, and their aetiology has often been the subject of speculation and controversy. Occasionally the indisputable evidence of a congenital origin is provided at necropsy on a stillborn foetus, but more often the authors' conclusion as to whether the disease is congenital or acquired is based on embryological and histological data supported by a wealth of conjecture. The purpose of this paper is to present a group of cases in which further light is shed on the development of lung cysts by prolonged clinical observation and serial radiography, and to develop the concept that in most of these cases the disease is acquired rather than congenital.

\section{Congenital Theory}

The frequent finding of pulmonary cysts in young children is not enough to establish a developmental origin, and the arguments in favour of this aetiology rest on the occasional observation of similar cysts in the foetus, their occurrence in association with other structural anomalies, the finding of abnormal histological patterns unlikely to have resulted from an acquired cause, and on the opinion of knowledgeable pathologists who have made a detailed study of individual cases. The literature supporting a congenital origin of lung cysts will be reviewed before passing on to argue how such cysts could have developed in postnatal life.

The cyst of the lung described by Fontanus was found in an infant 3 months old. Bartholinus (1687) mentioned a child of 4 years with cystic dilatations in the left upper lobe. In the last century many congenital lung cysts were reported by Meyer (1859), Biermer (1860), and Barlow (1880). Grawitz (1880) reported the case of an infant $5 \frac{1}{2}$ months old who showed epithelial-lined cysts throughout both lungs which did not communicate with bronchi. There was an excess of cartilage in the cyst walls and a complete lack of fibrous tissue. Löhlein (1908) observed epithelial and connective tissue hyperplasia, and suggested that the cysts were neoplastic foetal adenomata. This view had also been held by Couvelaire (1904) who found in the large middle lobe of an infant of 6 days old multiple small fluid cysts lined by cuboidal or columnar epithelium and surrounded by alveoli of normal appearance. Hueter (1914) thought arrest in bronchial development was the cause of lung cysts, because the spongy lobe he observed in a stillborn child was filled with acini lined by low cuboidal epithelium, but no bronchi entered the part. Virchow (1862), and Klebs (1889) argued that multiple cysts were anomalous lymphatic dilatations similar to those seen in other parts of the body such as the kidney. Klebs was of the opinion that there were many more cysts than could be accounted for by bronchial dilatation. Balzer and Grandhomme (1886) produced evidence that bronchiectasis and cyst formation were common in congenital syphilis. Sauerbruch (1934) considered that part of the developing left bronchial tree may be constricted by pressure of the heart or by the duct of Cuvier and that, depending on the stage of development at which the stricture occurred, these isolated parts became large cysts, multiple grape-like cavities, or bronchiectasis of medium bronchi.

Most of the earlier writers on cysts in the lung did not distinguish between solitary or multiple round cysts and the lesser degrees of bronchial dilatation which are now called bronchiectasis. Laennec (1821) described cases of dilatation of the bronchi in which there were marked inflammatory changes and a history of chronic pulmonary infection. The view that bronchiectasis is an acquired condition has now almost entirely replaced the congenital hypothesis, and has resulted in the absurd popular assumption that bronchial dilatations from cylindrical to gross saccular are of acquired origin, but the slightly greater degree in round cysts 
is assumed to be caused by developmental malformation. In 1933 Kartagener recorded the extraordinary frequency with which transposition of the viscera is associated with bronchiectasis. Both these conditions are rare, yet a quarter of the former have bronchial dilatations, and the frequent co-existence of these features has been confirmed by Adams and Churchill (1937) and Olsen (1943). Other authors have shown a familial incidence of this association, Torgersen (1946) and López Areal (1944), and it has been claimed that transposition of the viscera is inherited as a rare recessive character (Cockayne, 1938). Because bronchiectasis occurs so often in patients with this congenital anomaly, it has been suggested that the bronchial dilatation also has a developmental origin. With regard to this last point, it is interesting to note that very few cases with situs inversus totalis show the type of solitary pulmonary cyst or polycystic lung disease which is generally regarded as congenital. Andrews (1949) recorded a recent example of the latter in which there was dextrocardia and cysts in the left upper lobe.

There will be no discussion in this paper of the round opacity in the chest which may be produced by a fibroma, lipoma, nerve tumour, secondary malignant growth, hydatid cyst, cyst of gastric epithelium, or loculated interlobar effusion; nor will mention be made of the spurious air-containing lung cyst suggested by an eventration of diaphragm, diaphragmatic hernia or small pneumothorax. Supernumerary lung lobes and sequestered pulmonary tissue outside the lung are germane to this study and frequently contain cavities. A supernumerary lobe, when well demarcated, can be confused with a lung cyst, particularly an azygos lobe in the upper chest or the rare caval lobe in the lower. Ruge (1878) described a small accessory lobe receiving its blood supply from an intercostal artery, and Humphry (1885) another which was attached by a narrow pedicle to the descending aorta. Muus (1904) and Linser (1899) have reported intrathoracic collections of cystic aberrant lung tissue with no connexion with the rest of the pulmonary parenchyma, and Vogel (1899) and Seltsam (1905) found an accessory lung lobe the size of the spleen under the left leaf of the diaphragm. Misplaced pulmonary cysts lined by bronchial epithelium are more often located in the mediastinum about the bifurcation of the trachea (Gold, 1921; Carlson, 1943; Brown and Robbins, 1944; Allison, 1947). These cysts are usually filled with fluid, but some have a bronchial connexion with the trachea or main bronchial stem and contain air. Cystic pulmonary tissue lined by ciliated columnar epithelium has even been found embedded in the liver (Friedreich, 1857; Zahn, 1896).
Congenital sequestration of lung tissue can also be intralobar, as has been pointed out by Pryce, Holmes Sellors, and Blair (1947). This consists of an ectopic pulmonary mass with usually a blind bronchus and abnormal arterial supply situated in one of the lower lobes. The condition is clearly developmental, the tissue is often cystic or bronchiectatic, carbon pigmentation is generally lacking, and the whole is apparently due to the fact that a portion of the developing lung acquired in very early life a blood supply from one of the dorsal aortae instead of from the ventral aorta or pulmonary artery. Though the main arterial supply to such sequestrated pulmonary tissue arises from the aorta, the artery itself is usually an elastic structure resembling a pulmonary rather than a systemic artery.

Lung cysts have been reported in patients of all ages. They may occur throughout both lungs, but are usually confined to one side and frequently to one lobe. One, or perhaps a collection of three or four cysts, may be visible radiologically. Others, being too crowded together or too small, may not be visualized radiologically, though in the macroscopic specimen they are obvious, and sometimes appear as a honeycomb of multiple small cysts filled with glairy fluid or air. Microscopy reveals columnar ciliated bronchial epithelium in the cyst wall, though it may be cuboidal if there has been much distension, and after infection squamous metaplasia can occur, or almost total denudation of the mucosa. Outside the epithelium, normal elastic and muscle tissue may be found, but sometimes a variable amount of fibrous connective tissue is seen with bronchial wall elements, such as cartilage, glands, and smooth muscle arranged irregularly. In a number no normally developed terminal respiratory units can be found about the cystic lung segments. The albuminous fluid material in uninfected cysts is composed of mucus and cellular debris. The morbid specimen, in patients who have lived for more than a few years, fails to show lung pigmentation in the cystic area, though it is present in the rest of the parenchyma and confirms the view that the cysts are congenital, or arise in very early infancy.

The bronchial tree develops with the trachea from undifferentiated mesenchyme enclosed in the primitive branchial arches. As the foetus grows, this tissue descends into the thorax and spreads out on either side as the primitive lung bud. The heart and great vessels are also derived from mesenchyme enclosed by the branchial arches and descend into the thorax in front of the endodermal tube, which will later divide into two to constitute the oesophagus and trachea. The bronchial tree develops as small 
ramifications of solid endodermal tissue which become canalized almost immediately. In developmental or congenital cystic disease of the lungs an unknown process is thought to interfere with canalization at some point proximal to the termination of the bud; distal to this point canalization begins again, producing an isolated canalized segment lined by normal bronchial mucous membrane. The mucosa and glands assume their normal secretory function, but when fluid is secreted faster than it can be absorbed, or drainage into the lymphatics and blood stream is imperfect, the material accumulates and a fluid cyst is formed. The lung enlarges enormously after birth, and a few air cysts result from rupture of fluid cysts into the bronchial system and replacement of their contents by air. The majority of congenital air cysts are due to tremendous distension of some bronchi by a raised air pressure beyond a developmental stenosis or check valve formed by redundant epithelium; such distension occurs because of a congenital weakness in the bronchial wall or failure in development of the supporting parenchyma. The enlargement of air-containing cysts is favoured by a negative intrapleural pressure and widening of the bronchi on inspiration. The narrow ostia connecting some cysts with patent bronchi are situated tangentially on the circumference of the cysts, and assume what the French refer to as a bec de flute appearance. These may act as check valves by allowing the entrance of air on inspiration and preventing its escape through compression of the opening during expiration. Infection is frequent in pulmonary cysts because of the stagnation of secretions within them, and in nearby bronchi partially occluded by swelling of the cysts. When there is no stenosis of the ostia connecting cysts to bronchi, and secretions from the cysts can drain away easily, the presence of cystic disease of the lungs may not be diagnosed until some episode occurs in later life, such as a haemoptysis or infection, which brings the condition to light. Congenital lung cysts are generally classified as simple or multiple, fluid or air-containing and, according to whether the bronchial opening is closed, open, or valvular.

The literature on ' congenital' cysts of the lung has been extensively surveyed by Koontz (1925) and Schenck (1937). The latter recorded the site and type of all the congenital cystic lungs described up to 1937 , together with the age when they were recognized, and the chief symptoms of the patient. Altogether there were 374 cases in which the type of cyst was mentioned. They are tabulated below.

Lung cysts with a wall structure characteristic of bronchial tissue have been found at necropsy in stillborn foetuses, as reported by Meyer (1859), Hondo (1904), Hammar (1904), Zipkin (1907), Smith (1925), and Wolman (1930). Wolman's case was a premature baby of six months' gestation. The large right lung was full of cysts, and displaced the mediastinum and heart into the left hemithorax. Pressure on the cysts did not collapse them. The cysts varied in size from $1 \mathrm{~mm}$. upwards, and the epithelium of the smaller cysts was cuboidal as in the alveoli, but larger cysts had ciliated columnar epithelium as in bronchi. Elastic fibres were not seen in the cyst walls, possibly because these develop at a later stage in pregnancy, and there were no inflammatory signs. Wolman considered that the cysts were due to an anomalous pinching-off of some developing bronchi and distension with secretion. He did not explain how the majority of the cysts came to be empty at necropsy; they must have contained gas or fluid at some time because of their round shape. Zipkin's case is particularly interesting because the bronchi of the large cystic left lung contained a layer of striated muscle; the right lung was aplastic and there were several congenital heart defects. The literature also includes numerous records of pulmonary cysts that have been found at necropsy in newborn infants less

Analysis of 374 Cases of Lung Cysts in Children (Schenck, 1937)

\begin{tabular}{|c|c|c|c|c|c|c|c|}
\hline \multirow[b]{2}{*}{ Solitary } & of Cyst & $\begin{array}{c}\text { Distributior } \\
(\%)\end{array}$ & & $\begin{array}{l}\text { Age of Recogn } \\
\text { in } 368 \mathrm{Cas}\end{array}$ & ion & Symptoms & \\
\hline & Multiple & \multirow[b]{2}{*}{$\begin{array}{l}\text { Right lung, } \\
\text { Left lung, } \\
\text { Bilateral, }\end{array}$} & \multirow[b]{2}{*}{$\begin{array}{l}42 \\
37 \\
21\end{array}$} & \multirow[b]{2}{*}{$\begin{array}{l}\text { At birth, } \\
0-1 \text { year, } \\
1-15 \text { years, } \\
\text { Over } 15 \text { years, }\end{array}$} & \multirow[b]{2}{*}{$\begin{array}{r}36 \\
57 \\
68 \\
207\end{array}$} & \multirow[b]{2}{*}{$\begin{array}{l}\text { Cough, } \\
\text { Dyspnoea, } \\
\text { Expectoration, } \\
\text { Cyanosis, } \\
\text { Fever, } \\
\text { Haemoptysis, } \\
\text { Malnutrition, } \\
\text { Thoracic pain, }\end{array}$} & \multirow[b]{2}{*}{$\begin{array}{r}217 \\
154 \\
152 \\
75 \\
72 \\
52 \\
50 \\
39\end{array}$} \\
\hline $\begin{array}{l}141 \\
49 \text { (fluid) } \\
55 \text { (air) } \\
37 \text { (valvular expansile) }\end{array}$ & $\begin{aligned} 233 \\
38 \text { (fluid) } \\
188 \text { (air) } \\
7 \text { (valvular expansile) }\end{aligned}$ & & & & & & \\
\hline
\end{tabular}


than 1 month old (Couvelaire, 1904; Stoerk, 1897; Pappenheimer, 1912; and Koontz, 1925). Pappenheimer's case lived three hours. At necropsy, the right upper lobe was full of cysts which could not be filled by bronchial injection, but he thought that microscopically there was continuity between the bronchi and the cysts. The obstruction was due to redundant bronchiolar epithelium. Koontz's case showed similar findings.

In summary, it can be stated that a congenital origin is generally assumed for most pulmonary cysts in childhood, because very similar cysts are found in the lungs of stillborn and newborn infants, aberrant lung tissue is usually cystic, and some few cases have shown associated malformations of other structures. The cysts are bronchial dilatations which may or may not be connected with the rest of the bronchial system, their lining is composed of respiratory epithelium, their walls are formed of bronchial structures which are frequently arranged in an irregular manner, and some appear to contain tumour-like masses. There is in the stillborn and newborn case little evidence of inflammatory pathology either in the form of infiltration with polymorph or lymphocyte cells, or of destruction in the cyst walls and replacement by fibrous tissue.

The following case is an example of a congenital cyst of lung.

The baby was born at 34 weeks' gestation, and weighed $3 \mathrm{lb}$. $4 \mathrm{oz}$. He succumbed after five minutes of life. The mother was a primipara aged 30 . A year previously she had consulted her doctor because of sterility, and an undeveloped uterus was found. After dilatation and curettage and injections of gonadotrophic

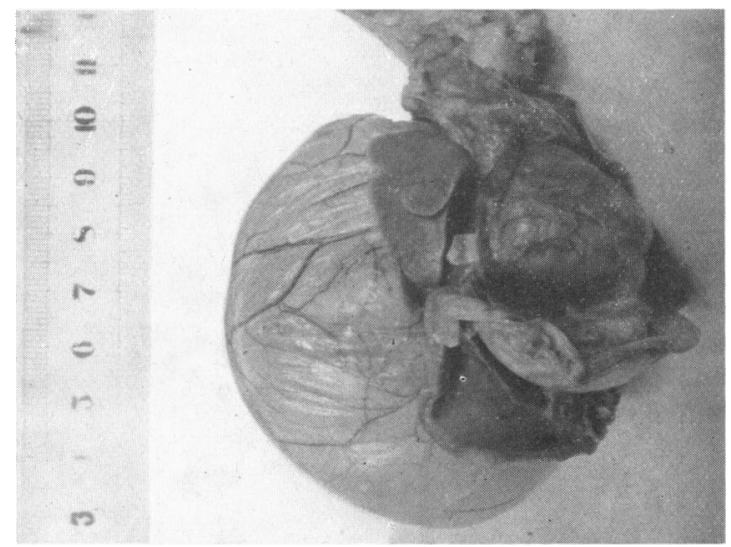

FIG. 1.-Congenital lung cyst found in a child who died five minutes after birth (Case 1). hormone she became pregnant. The pregnancy was normal, and no reason could be found for the premature rupture of membranes which precipitated labour.

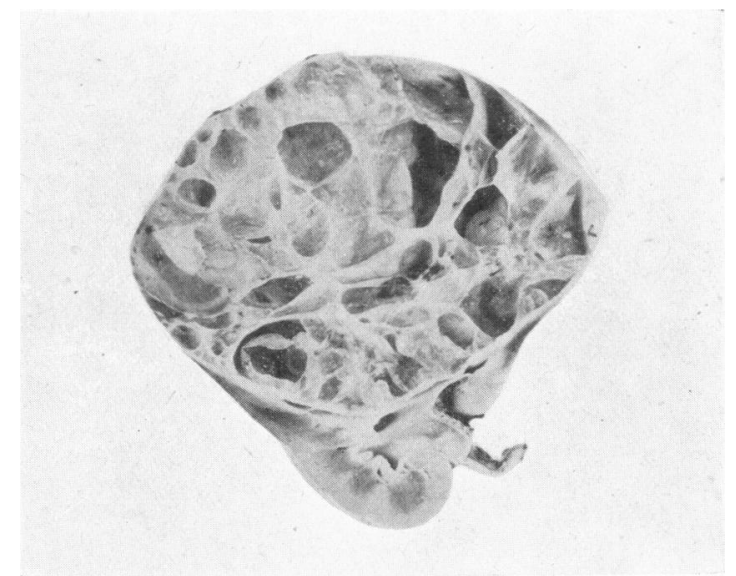

FIG. 2.-Cystic hygroma of right kidney (Case 2).

A necropsy was performed on the infant 24 hours after birth. There was a small subarachnoid haemorrhage over the brain. The abdomen contained a considerable amount of ascitic fluid, the cause of which was not found. The only other abnormal findings were in the thorax. The pleural cavities were clear. The right lung was bi-lobed; the third lobe appeared to be replaced by a cystic swelling occupying almost all the right pleural cavity and containing about $10 \mathrm{oz}$. of straw-coloured fluid (Fig. 1). Pressure on the cyst did not empty fluid into a bronchus. Traversing behind the cyst were the oesophagus, which was atretic here, and the aorta. Behind both of these an extension of the cyst crossed the midline. The right lung was markedly hypoplastic. The heart was normal.

The cyst was lined by low cuboidal epithelium and the section also showed a blood vessel and a nerve. The presence of cuboidal epithelium signifies that the cyst was pulmonary and not formed from pleural, vascular, lymphatic, or oesophageal tissue.

Case 2 shows a cyst which is probably of congenital origin.

Case 2. This girl was admitted to hospital when $1 \frac{1}{2}$ years old because of failure to thrive for six months, dyspnoea, and a swelling in the right flank for two weeks. The abdominal mass was found at operation to be a huge lymphangiomatous tumour of the right kidney, lined by flat endothelial cells (Fig. 2). It was noted at the time of admission that the trachea and mediastinum were deviated to the left and a radiograph showed that the right chest was filled by a huge air cyst (Fig. 3). The cyst had a bronchial connexion and appeared to be 
enlarging, but after a needle was introduced to let off some air a tension pneumothorax developed, and the cyst deflated to a small area of lymphangiomatous material attached to the right lower lobe, diaphragm,

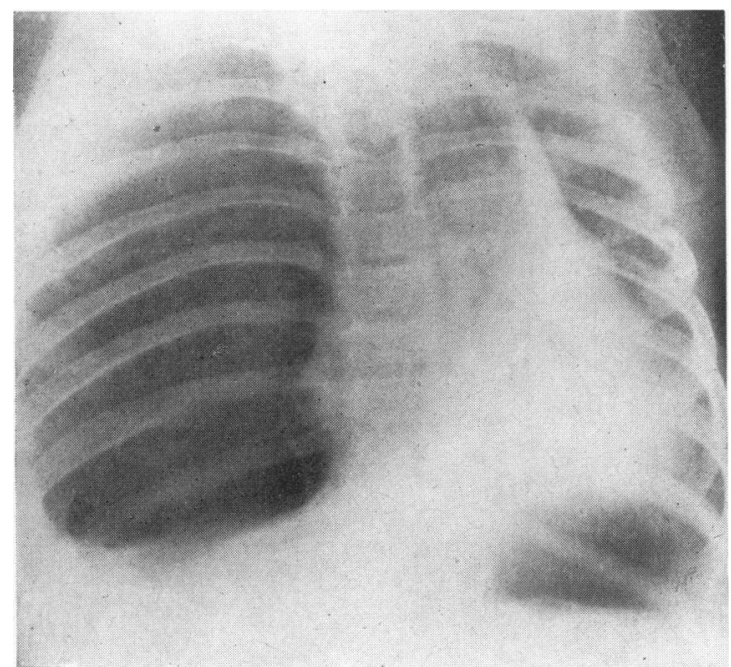

FIG. 3،-Large air cyst filling the whole right chest in a child of $1 \frac{1}{2}$ years (Case 2).

and parietal pleura. At operation, the three lobes of the right lung were tightly collapsed, and it was observed that the medial part of the cyst had previously herniated through the upper mediastinum and reached the lateral wall of the left upper chest. The cyst was removed, and the right lung subsequently inflated completely. Histological examination of a portion of the cyst wall revealed a lining of endothelial cells similar to that of the cystic hygroma of the right kidney. The lymphangiomatous tumour attached to the right lung could be taken as a congenital lesion, but its connexion with a bronchus and subsequent inflation might be due to an acquired valvular bronchial mechanism produced by pressure of the tumour.

\section{Acquired Hypothesis}

It is not possible to present the case for an acquired aetiology of pulmonary cysts with an equal wealth of supporting opinion from the literature concerned, but it should be mentioned that the evidence for a developmental aetiology, in many cases described as congenital, has been slender or even equivocal. The burden of this article is not to criticize the observations of others, nor to doubt that some lung cysts are indeed developmental, but rather to present clinical evidence to support the hypothesis that the majority of pulmonary cysts are acquired.

Acquired pulmonary cysts are generally the product of mechanical and inflammatory forces. The result of the latter hypothesis is best seen in the morbid specimen, while the former can only be estimated, though crudely, in life, and it is therefore obviously difficult to offer an adequate classification. There are bound to be gradations from cysts due to purely mechanical factors to those necrotic cavities which are entirely the result of infection. Misconceptions often result when disease processes are too rigidly classified, but as clarity demands some subdivision of the subject, the following has been used: (1) emphysematous and interstitial bullae, blebs and pneumatocoeles; (2) lung abscess, pulmonary infarction with necrosis, and bronchial distension; (3) tuberculous cavitation; (4) multiple honeycomb lung; and (5) traumatic cysts.

Emphysematous and Interstitial Bullae, Blebs, and Pneumatocoeles. Heller (1885) and Francke (1894) attributed so-called congenital cystic disease of lungs to the saccular dilatations of small bronchi and bronchioles formed in atelectatic lungs which did not expand after birth. Other writers ascribed honeycomb cysts with a cuboidal cell lining to the over-distension of the relatively few alveoli which develop in an atelectatic lobe. The following case illustrates the possible mechanism.

Case 3. This girl was noticed to be breathing poorly after birth. A chest radiograph taken four days later showed atelectasis of the whole right lung and a small pneumothorax on the left side. There was also a translucency on the right side in the region of the third to fifth thoracic vertebrae which had a sharp edge laterally. This was suggestive of partial aeration of the upper lobe or an air cyst, but it was in fact part of the over-inflated left upper lobe which had herniated across the mediastinum. Another radiograph 16 days later

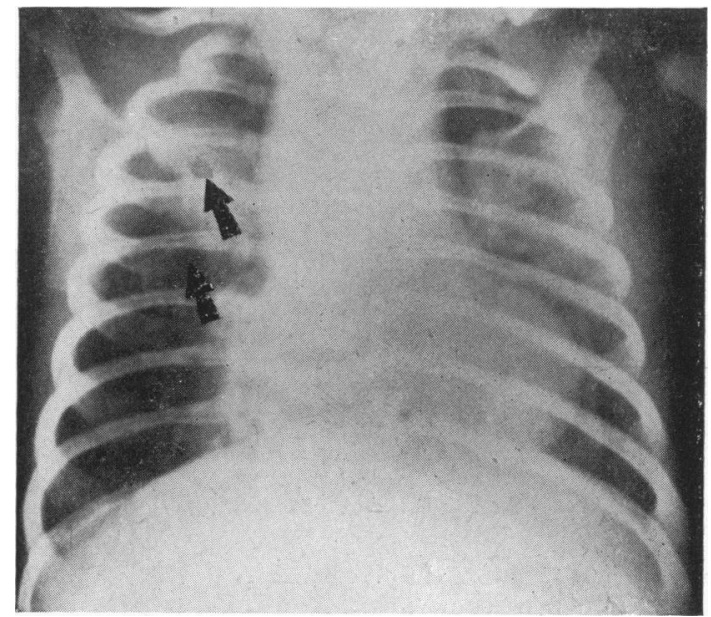

FIG. 4.-The chest of an infant, aged 4 weeks, showing two cystic areas, one in the atelectatic right upper lobe and the other in the middle lobe. There is also a pneumothorax on the left side (Case 3). 
showed that the right lower and middle lobes had expanded, the pneumothorax cleared, and the heart was more central. There was also some expansion of the right upper lobe together with a translucent area resembling a cyst in its lower part. Further radiographs at 4 weeks old (Fig. 4) revealed two cystic spaces in the right upper lobe and a return of the pneumothorax on the left. The cysts disappeared during the next two months, but the lobe took three years to expand fully. At the end of this time a bronchogram showed bronchiectasis in the posterior bronchi (Fig. 5).

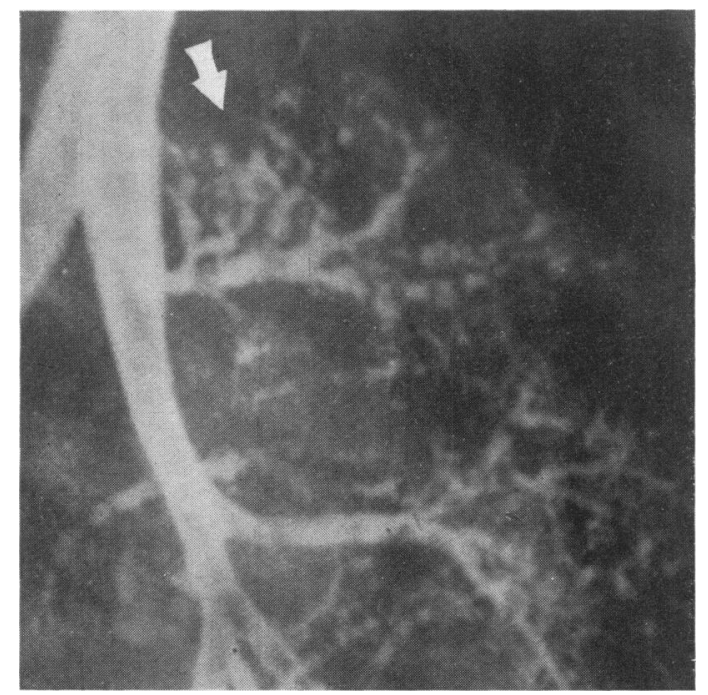

FIG. 5.-Oblique view of part of the right bronchogram done at the age of 3 years. There is bronchiectasis in the posterior segment springing from the eparterial bronchus just below the bifurcation of the trachea (Case 3).

The two translucent areas resembling cavities are either over-inflated lobules which contrast with the opacity of the atelectatic lobe, parenchymatous or interstitial bullae, or two bronchi distended into air cysts. The over-distension of alveoli may be either compensatory, or the result of valvular bronchial obstruction. The septa between emphysematous alveoli are liable to atrophy so that bullae are formed and if the bronchial obstruction remains, or infection thickens the cavity walls, these lung cysts are likely to persist. The residual bronchiectasis is in favour of the cysts being of bronchial origin, but it may be coincidental.

Case 4. This case demonstrates an almost similar radiographic appearance in a young baby, but with a different aetiology. This boy was the first live birth after six miscarriages. He was born a month prematurely, weighing $6 \mathrm{lb} .7 \mathrm{oz}$. and had blue asphyxia. When 2 weeks old, he developed a cough with expectoration of mucus but radiologically the chest was normal at the age of 3 weeks. Despite the cough, he appeared fairly well and when he was again examined at 5 weeks old he had gained a pound in weight: the temperature was $99^{\circ}$ F.; pulse $150 / \mathrm{min}$. and respirations $35 / \mathrm{min}$. Bouts of coughing caused vomiting and dyspnoea. The chest revealed a slight wheeze in the right upper half and some bilateral basal crepitations. A radiograph showed complete opacity of the left upper lobe with a rounded lower border (Fig. 6). He was given a course of sulphamezathine. His general condition remained good, and the pulse and temperature were unaltered during the next week. His respirations, however, rose to $50 /$ min., and he coughed up blood-stained mucopus (W.B.C. 24,400/c.mm.). A post-nasal swab grew pneumococci, $H$. influenzae, diphtheroids, and Staph. albus. At the age of 6 weeks one large and several small round clear areas appeared in the middle of the opacity in the left upper lobe (Fig. 7). Two months later the apparent cysts had cleared. The lobe was not fully expanded three years later when a bronchogram was done showing bronchiectasis in the apical and posterior segments (Fig. 8).

Without the earlier radiography showing a clear lung field on the left side, this child might have been considered as a case of infected atelectasis. In fact, he had pneumonia in the upper lobe, and as this was resolving, several collections of alveoli and small bronchi became over-distended owing to a check valve obstruction to their proximal bronchi. In the past many such cases have been diagnosed as fluid-containing congenital cysts of lung which ruptured into bronchi, the mucus then being coughed up and replaced by air. It is said that many such developmental cysts clear completely, but the advent of infection sometimes causes a valvular obstruction and distension of the cavities with air. In this child the emphysematous bullae and distended terminal tubes could have persisted as lung cysts had clearing of their bronchi not taken place and allowed them to deflate.

These transient cysts have been called 'pneumatocoeles' to distinguish them on the one hand from permanent atrophic emphysematous bullae such as are found in adults with chronic bronchitis, asthma, or in lung fields scarred by old tuberculosis; and on the other hand from the pulmonary cavity of a lung abscess, localized infarction with necrosis of the parenchyma, tuberculous excavation or traumatic lung cyst. The conception of a pneumatocoele is recent, but there are now many descriptions of them (Peirce and Dirkse, 1937; Benjamin and Childe, 1939; Caffey, 1940; Almklov and Hatoff, 1946).

Pneumatocoeles are cavities on the surface or in the substance of the lung. They generally occur in children during the course of pneumonia and are sometimes multiple. Many contain fluid, their size and number may vary from time to time, and they show a marked tendency to complete resolution within a matter of days or weeks. The fact that pneumatocoeles tend to appear a few days after the start of pneumonia and contain inflammatory exudate, causes them to resemble a lung abscess very 


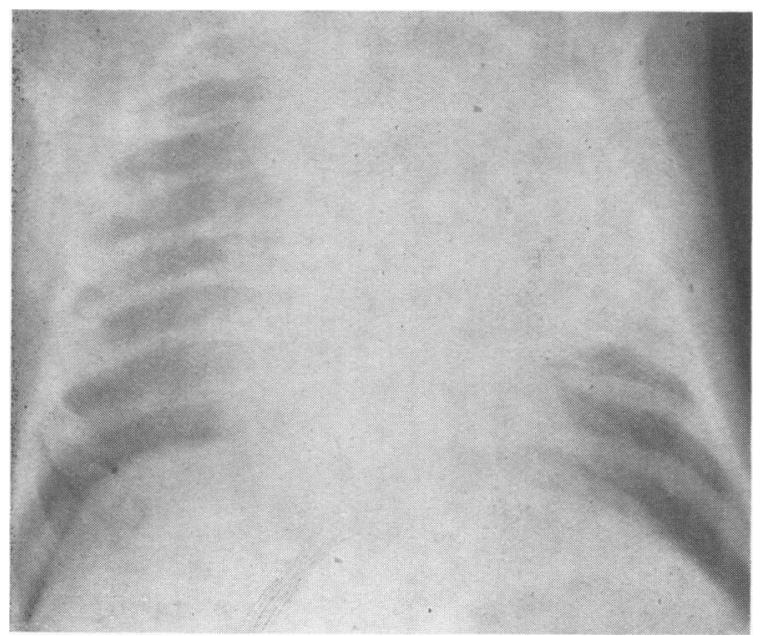

FIG. 6.-Pneumonia left upper lobe; age 5 weeks (Case 4).

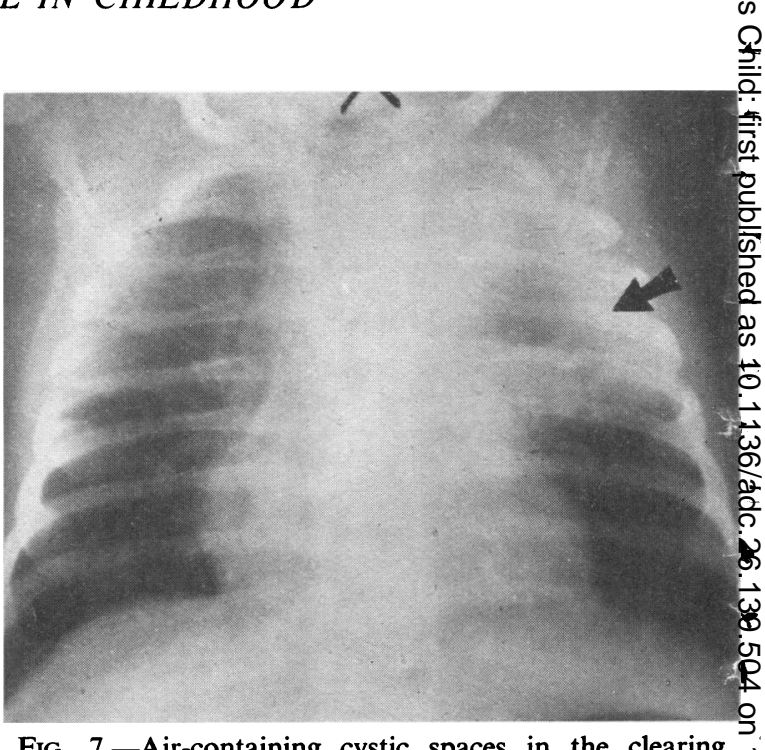

FIG. 7.-Air-containing cystic spaces in the clearing pneumonic lobe; age 6 weeks (Case 4).

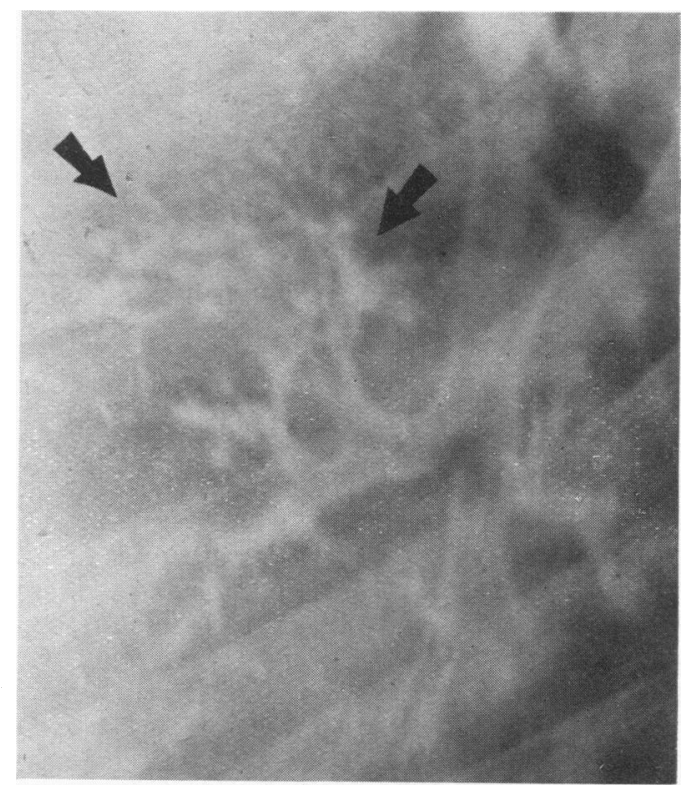

Fig. 8.-Part of oblique left bronchogram at the age of 3 years. Bronchiectasis in the left apical and posterior bronchi (Case 4). 
closely, but their rapid development, fluctuating size and tendency to early and complete resolution are distinctive; furthermore the patient's clinical condition is seldom affected by their appearance and the prognosis of the illness is not made worse.

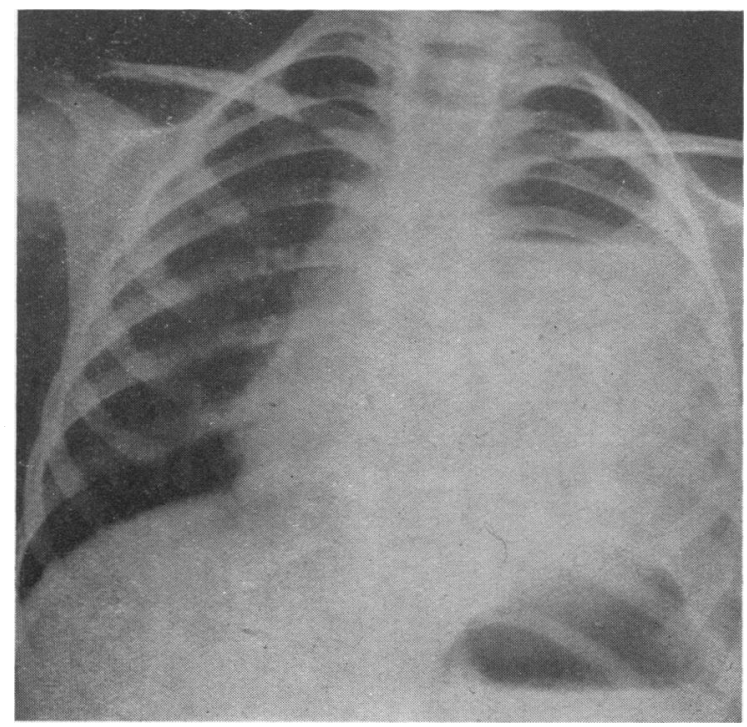

FIG. 9.- Pneumatocoele containing air and fluid in a child on the fifth day of pneumonia involving the left lung (Case 5).

It is thought that pneumatocoeles are produced by a valvular obstruction in small bronchi or bronchioles which causes the peripheral air pressure to rise and distend the local alveoli, bronchioles, or terminal bronchi into air-containing bullae. Such a mechanism seems probable, for air blebs and bullae are usual findings at necropsy on children with bronchopneumonia (McNeil, MacGregor, and Alexander, 1929); and obstructive emphysema of marked degree can sometimes be seen radiologically in infants with pneumonia (Snow and Cassasa, 1937). Laurell (1929) has demonstrated experimentally in fresh calf lung that raised intrabronchial pressure can produce emphysematous bullae both on the surface and deep in the substance of the lung which show up as round or oval cysts on radiography. Arnell (1927), and Doub (1928) have shown that the ring translucencies in the $x$-ray film of human lungs can be produced by emphysematous bullae surrounded by a rim of collapsed alveoli. The presence of a check valve bronchial mechanism has been confirmed by finding a raised gas pressure within pneumatocoeles (Lister, 1941; Caffey, 1940). A loculated pneumothorax can produce a round or oval air cyst radiographically as described by Fishberg (1917), but Peirce and Dirkse (1937) have shown by inducing a pneumothorax in one of their cases that the pneumatocoele was situated within the lung parenchyma.

It is quite possible that many pneumatocoeles are not emphysematous alveoli, but are in fact subpleural air blebs or interstitial pockets of air due to perforation of a small bronchus by ulceration or rupture of some alveoli allowing air into the tissue planes. The frequent occurrence of interstitial emphysema is proved by necropsy examination and histology in bronchopneumonia (McNeil, MacGregor, and Alexander, 1929). My earlier cases illustrate that when there has been bronchial obstruction and infection bronchiectasis can remain even when the cysts resolve satisfactorily. It is clear that a similar process may well result in diffuse cystic dilatations in the affected part. Pneumatocoeles may be of considerable size. When buried in the parenchyma of the lung they are round, but when more peripherally placed they can be elongated and resemble a pyopneumothorax as in the next case.

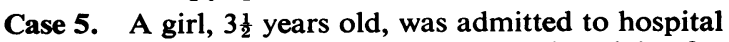
because of a cough, tachypnoea, fever and malaise for five days. She was given a course of sulphathiazole, but her temperature remained elevated for ten days. On examination, there were signs of pneumonia over the whole left lung and this was confirmed radiologically. Three days later her postero-anterior chest radiograph suggested a pyopneumothorax (Fig. 9), but a lateral view demonstrated a large, sausage-shaped pneumatocoele containing air and fluid. Another radiograph taken on the tenth day of her disease revealed two large cysts (Fig. 10). At no time did she expectorate any sputum

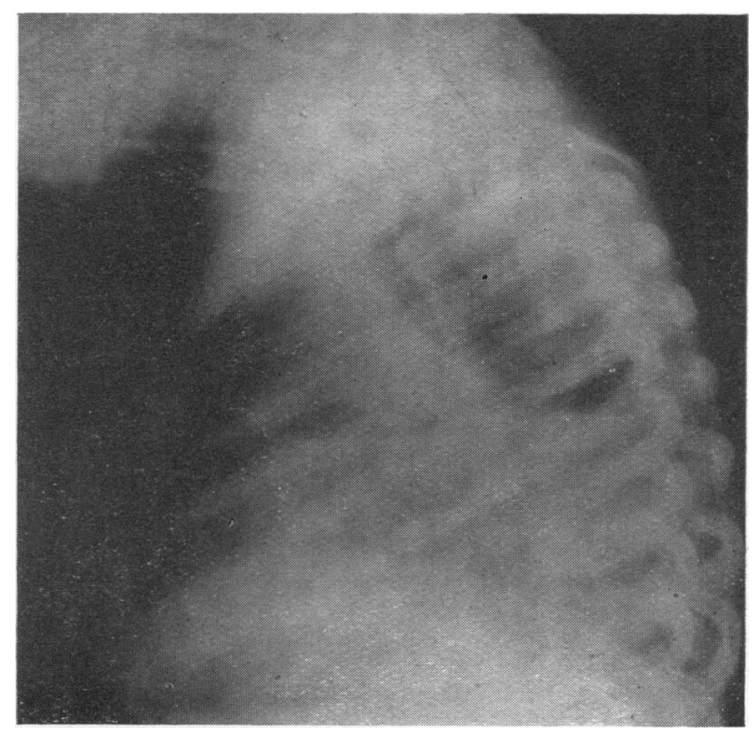

FIG. 10.-Two large pneumatocoeles on the tenth day of the pneumonia (Case 5). 


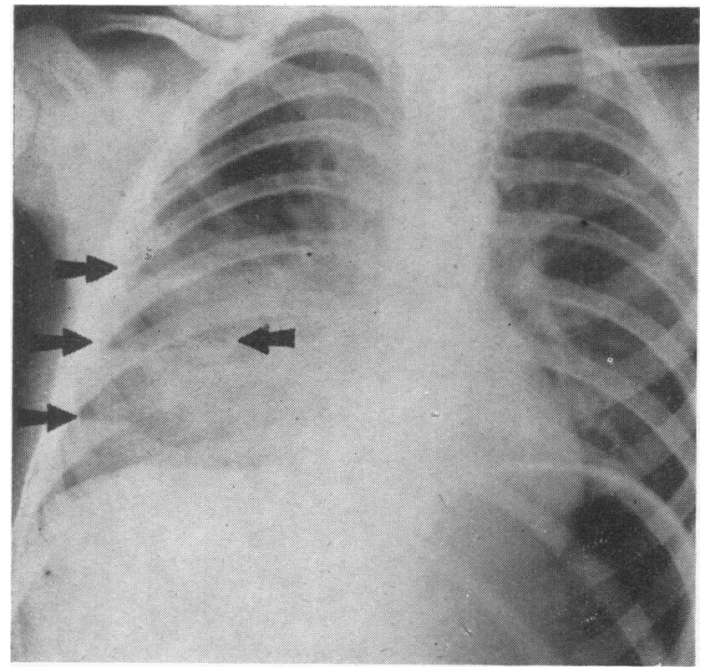

Fig. 11.-Four cysts in the right lower lobe with surrounding consolidation (Case 6).

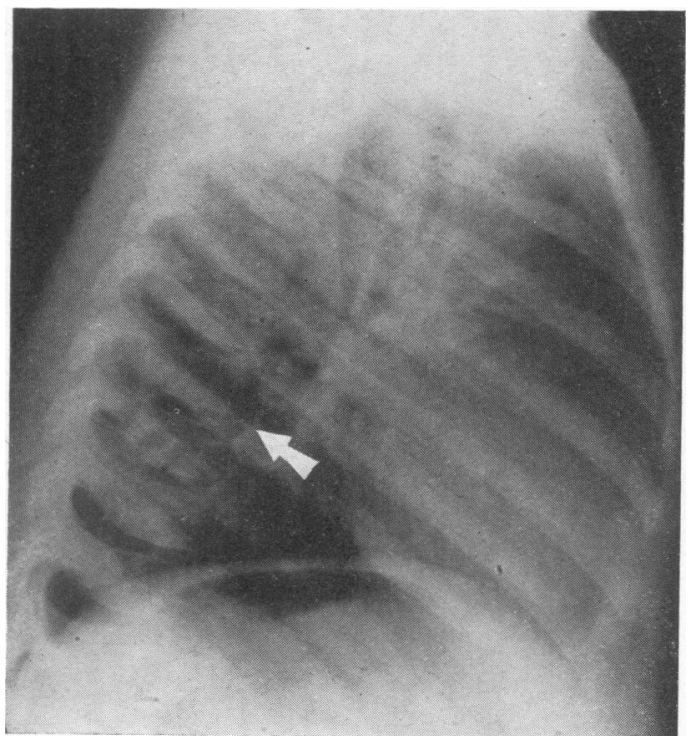

FIG. 13.-11 months later. Cyst now small and thinwalled in apical segment of right lower lobe (Case 6).

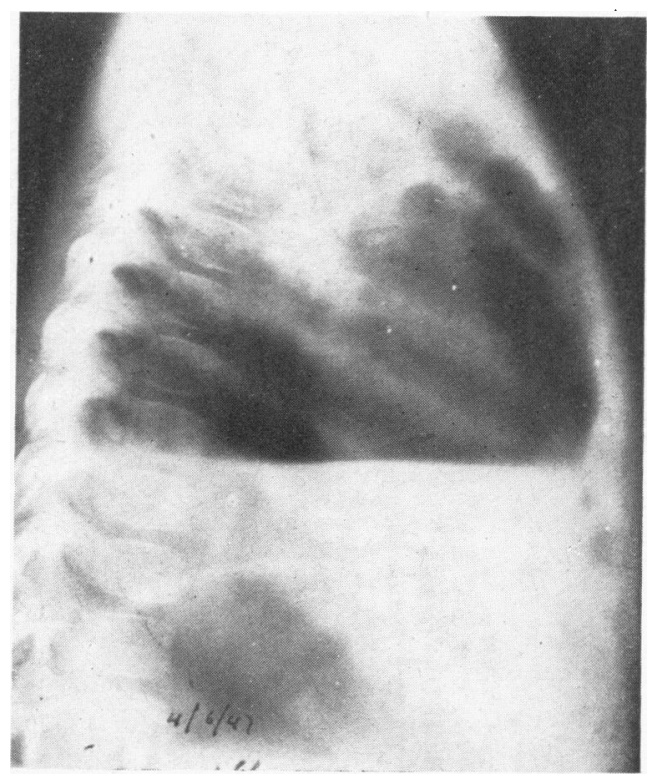

FIG. 12.-Six weeks later and following an acute pneumonic episode. Giant cyst formed by coalescence of the four previous cysts or the gross expansion of one of them due to a valvular bronchial obstruction (Case 6). 


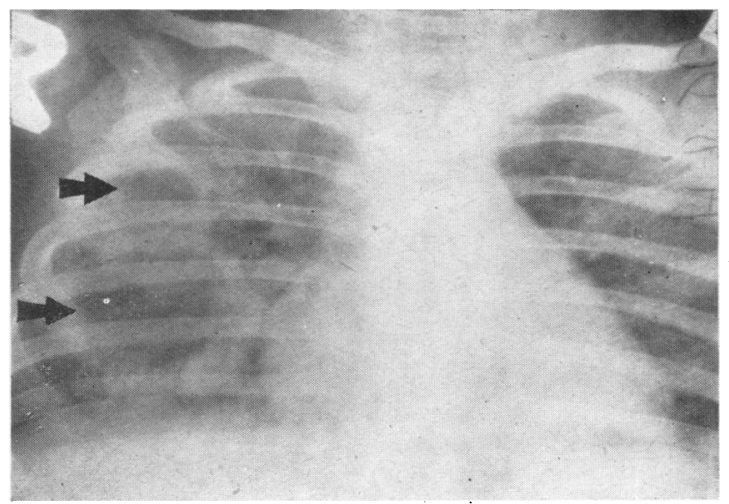

Fig. 14.-Two thick-walled cysts in the right lung surrounded by bronchopneumonic opacities (Case 7).

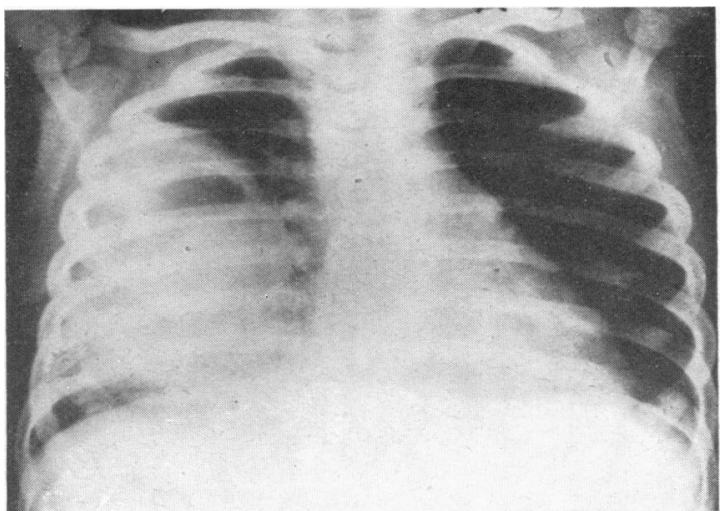

FIG. 15.-After three weeks of fever the radiograph shows one large cyst partly filled with fluid and surrounded by pneumonic consolidation (Case 7).

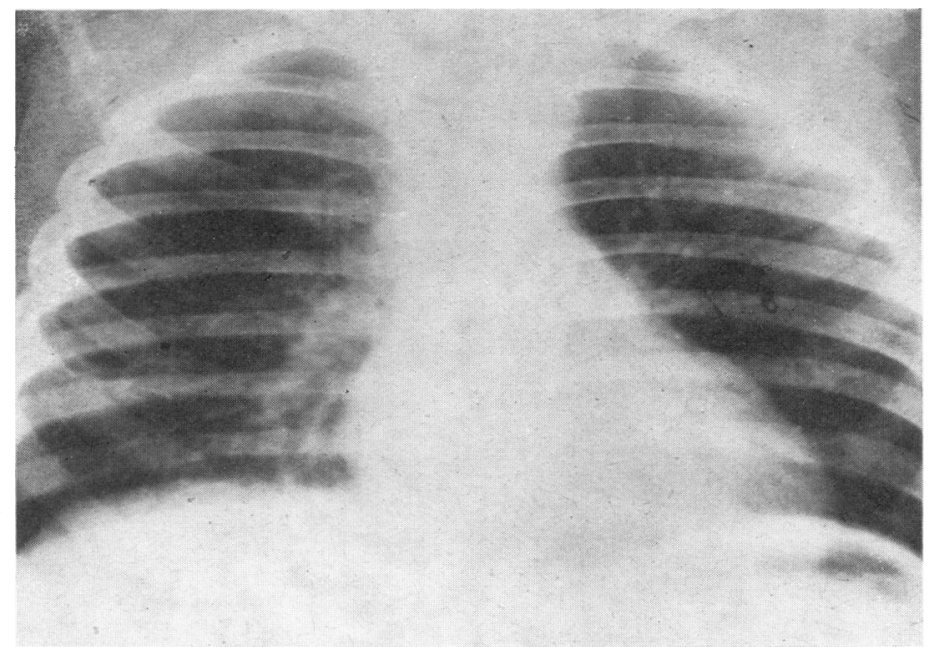

FIG. 16.-Four months after admission only faint circular outlines remain in the right lower zone signifying residual fibrosis (Case 7). 


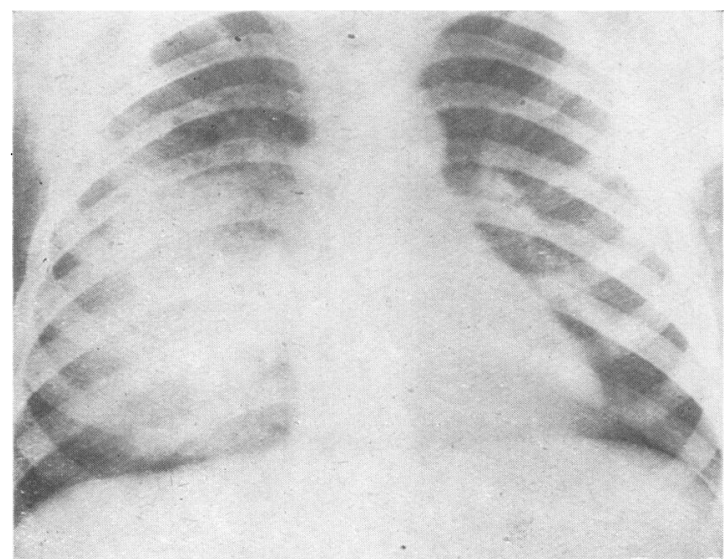

FIG. 17.-Two years before admission a rounded opacity in the centre of the right lung with a fluid level in the upper part caused by a large cyst filled with infected fluid and surrounded by consolidated and collapsed lung. This inflammation cleared in three months leaving one thin-walled air cyst (Case 8).

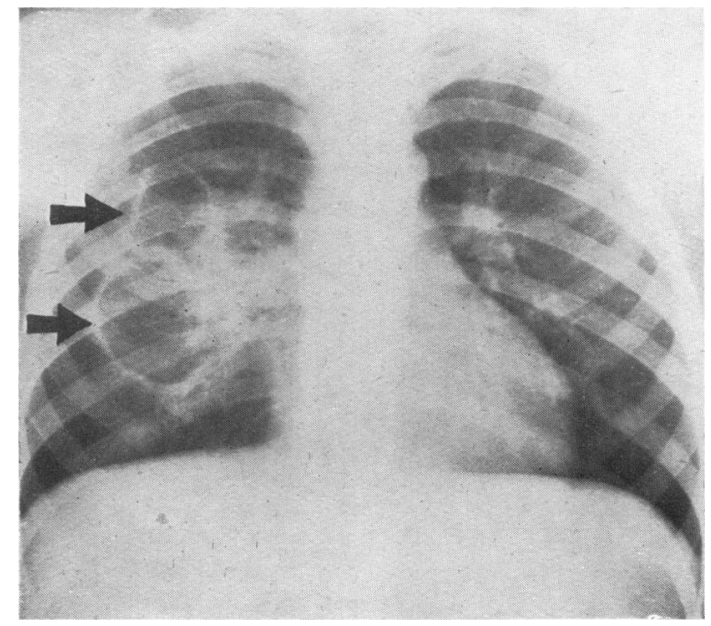

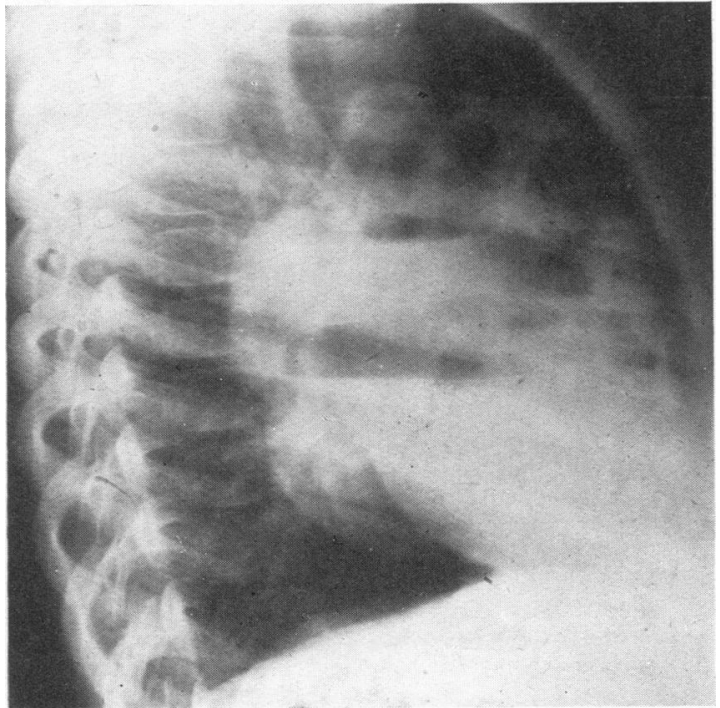

FIG. 18.-On admission pulmonary infection superimposed on the previous cyst has produced many more cysts containing infected fluid (Case 8).

Fig. 19.- One month later two large air cysts remain (Case 8). 
and her chest film was normal six weeks after the beginning of her illness.

Lung cysts starting as pneumatocoeles or lung abscesses may persist if the bronchial obstruction remains. Recurrent bouts of pneumonia are then not unusual and the thickened walls of the cavities decrease the chance of the cysts resolving completely. If the bronchial obstruction becomes a check valve the cysts may enlarge to an enormous size as in the next case.

Case 6. This girl of $2 \frac{1}{2}$ years had measles and pertussis four months before admission. She appeared to recover well from these, but five weeks before coming into hospital her cough returned and was accompanied by malaise. On admission she had the dense opacity of a pneumonia of the right middle and lower lobes. An earlier radiograph taken two and a half weeks before admission showed four cysts containing fluid and air in this area, surrounded by some pneumonic consolidation (Fig. 11). These cysts had probably developed during her earlier illness, and she now had an exacerbation of the inflammatory process. She ran a high fever for the next few weeks, there was no expectoration of sputum, and as the pneumonic process resolved the cysts again became apparent. A check valve obstruction to their bronchi, however, caused them to expand enormously and to coalesce into one enormous air cyst with fluid in its lower part which filled the hemithorax (Fig. 12). The cyst slowly deflated until 11 months later it was quite small, thin-walled and situated in the apical segment of the right lower lobe (Fig. 13). Two and a half years later the cyst had completely cleared and all that remained was a little local fibrosis.

The duration of lung cysts in childhood is very variable. Many last only a few days or weeks. Others, such as in Case 7, appear thick-walled, yet a bout of infection produces complete resolution. Some few, as in Case 8, persist unchanged through several bouts of infection and show little inclination to clear.

Case 7. This girl, aged $1 \frac{1}{2}$ years, had started a cold ten days previously, and became worse five days later by developing acute otitis media and bronchopneumonia. Her first radiograph on the tenth day of the illness showed two cysts embedded in the right lung, with mottled bronchopneumonic shadows about them (Fig. 14). She ran a high fever for the next six weeks. After three weeks, her chest film demonstrated a huge, rounded opacity resembling a fluid-filled cyst with a bubble of air in its upper part (Fig. 15). Three months later the cysts could not be clearly seen radiologically though a few circular traceries indicated some residual fibrosis in the previously affected area (Fig. 16).

Case 8. This boy came to hospital when five years old. At the age of 3 he had pneumonia, and a radiograph two months later demonstrated a large opacity which was then taken to represent a loculated interlobar empyema, but which was in all probability a cyst filled with infected fluid and surrounded by inflammatory exudate (Fig. 17). Within three months the opacity had cleared but a thin-walled cyst was clearly visible. This persisted for two years, when infection recurred, and the patient was again admitted to hospital. A radiograph of the chest at this time showed two large fluid-containing cysts and many small ones (Fig. 18). Had this radiograph been taken in the supine position instead of the erect, the alteration in the level of the fluid could have concealed the presence of cysts. Within two months the infection had almost cleared, but the two cysts remained clearly outlined (Fig. 19). The cysts gradually decreased in size, but, as at the time it was considered that the patient might have recurrences of pneumonia, the affected lobe was removed surgically.

When a large cyst is found in a child who has a history of pulmonary infection, it is probable that the cyst was caused by bronchial inflammation and obstruction. Cases are, however, seen without any history of an acute fever or chest disease which may have initiated the cysts.

Case 9. This boy was seen when 7 months old because of tachypnoea which had continued for three months. He had a normal birth. There was no asphyxia and no previous illness or chest symptoms. A radiograph of the chest (Fig. 20) revealed a large cyst filling the left chest, herniating across the upper mediastinum and compressing most of the lung parenchyma towards the heart and diaphragm.

A cyst such as the one described above is generally regarded as congenital in origin, because it has a

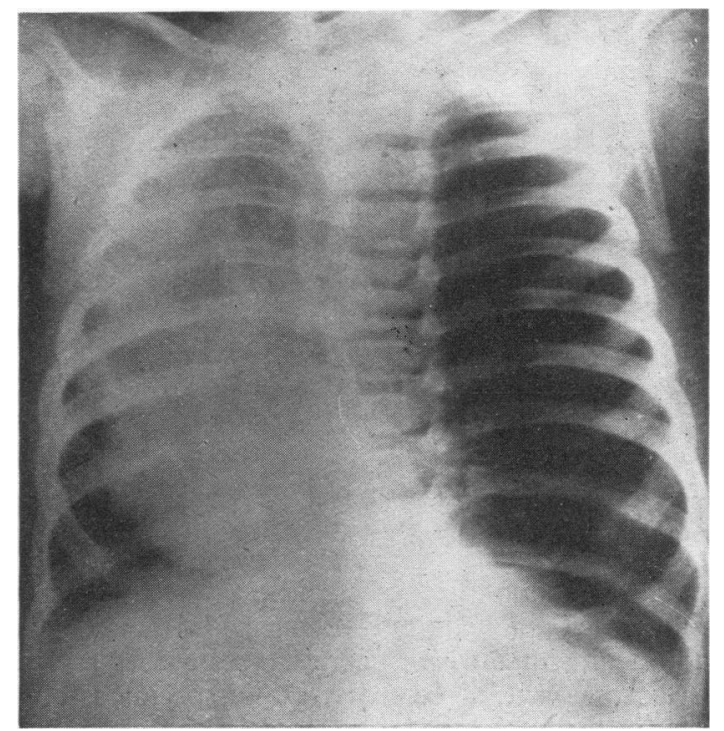

FIG. 20.-Aged 7 months. Large air cyst filling the whole of the left chest, displacing the mediastinum, and in the upper part herniating through the mediastinum into the right chest (Case 9). 
uniform lining of cuboidal epithelium, there is seldom a history of an acute pulmonary infection, and the cyst persists relatively unchanged for months or years. It could have started like my first case, which showed a true congenital cyst full of fluid, and in which, after rupture into a patent bronchus, the fluid was coughed up and replaced by air. I do not think many large air cysts occur in this way, for at operation a developmental deficiency or agenesis of parenchyma is not found, but the cyst appears rather to spring from within a lobe and to compress the rest of its parenchyma together with the other lobes about its periphery. According to one argument in favour of a congenital origin, it has been claimed that bronchi enter tangentially rather than directly into such a cyst, and that surrounding bronchi rarely show chronic inflammatory changes, whereas in saccular bronchiectasis the bronchi are almost invariably the seat of chronic inflammation and enter the sacs directly. Cysts and bronchiectasis of infective origin can, however, both develop without severe necrosis of lung tissue so that the walls have fairly normal bronchial layers and an epithelium rendered cuboidal by gross distension. Some cases of large solitary lung cyst show at operation or necropsy that the large cyst is surrounded by many smaller ones, but that the whole is confined to a single segment or subsegment of lung. Histology reveals that in these cavities there is often a good epithelium and elastica but little muscle and no seromucus glands or cartilage; furthermore the quantity of alveolar parenchyma in the part is deficient.

The protagonists of a congenital aetiology point out that muscle and cartilage would not disappear by atrophy or inflammation without leaving some tell-tale fibrosis. In favour of an acquired aetiology, on the other hand, it can be said that as alveolar elastica is poorly developed and stains faintly at birth (Linser, 1900; Dubreuil, Lacoste, and Raymond, 1936), and as bronchial elastica is not only less abundant at birth than it is afterwards, but appears later in foetal development than muscle or cartilage, it is unlikely that a congenital failure to form would affect the latter while the embryologically later elastica flourishes.

A large solitary air cyst filling the hemithorax has been considered to have a different origin from polycystic lung disease, because it is seen much more often among infants than in older children and adults, and not infrequently causes serious respiratory embarrassment. The macroscopic specimen, however, usually shows other cysts in the same lung area which were too small to be visualized radiologically, and in many cases were collapsed into elongated, tortuous channels by the gross enlargement of one particular cyst. It is possible that the large tension cavity in this boy originated from a valvular obstruction by developmentally redundant epithelium, but as similar cysts are found in older children it is probable that the check valve resulted from a patch of local bronchial inflammatory swelling or mucosal hypertrophy associated with allergy or irritation. Once a balloon cyst of air has developed containing a high air pressure it can to a large extent be self-perpetuating. The bronchus to the cyst comes to be situated tangentially to its circumference. It dilates and the ostium opens with each inspiration, but bronchial narrowing during the less forceful expiration combined with compression of the slit-like ostium between bronchus and cyst impedes the expulsion of air. The cyst usually increases in size until an equilibrium is reached or further expansion is restrained by the chest wall and maximum capacity of the mediastinum to withstand displacement.

Lung Abscess, Pulmonary Infarction with Necrosis, and Bronchial Distension

The picture in some of the cases of pneumonic consolidation just mentioned, followed by the development of cavities containing air and fluid, suggests that the underlying pathology may be that of a lung abscess. A pneumatocoele is regarded as a gross distension of alveoli, small bronchi, of bronchioles without much destruction of lunge parenchyma, whereas in a lung abscess there is a massive necrosis of lung tissue with the appearance of a cavity, as the dead material is removed by phagocytosis and bronchial drainage. Bronchial obstruction usually precedes the formation of a lung abscess, which is produced by localizing and enhancing the virulence of the accompanying infection. A lung abscess may therefore be a sequel to the aspiration of infected material after tonsillectomy or inhalation of a vegetable foreign body. Such episodes are, however, uncommon and the initial obstruction is generally due to swelling of the bronchial mucosa, or to viscid mucopus produced by bronchial inflammation or aspirated from the upper respiratory tract. Infected secretions retained beyond a block distend and then erode the bronchial walls and result in bronchiectasis. More virulent infection causes destruction of lung parenchyma as well, and produces the round cavity of a lung abscess. If the bronchial obstruction later becomes a valvular stenosis, air retained in the cavity can cause it to swell to a large size. An abscess cavity with a patent bronchial connexion has a natural tendency to decrease in size, but the raised intrabronchial pressure during the expiratory phase of 

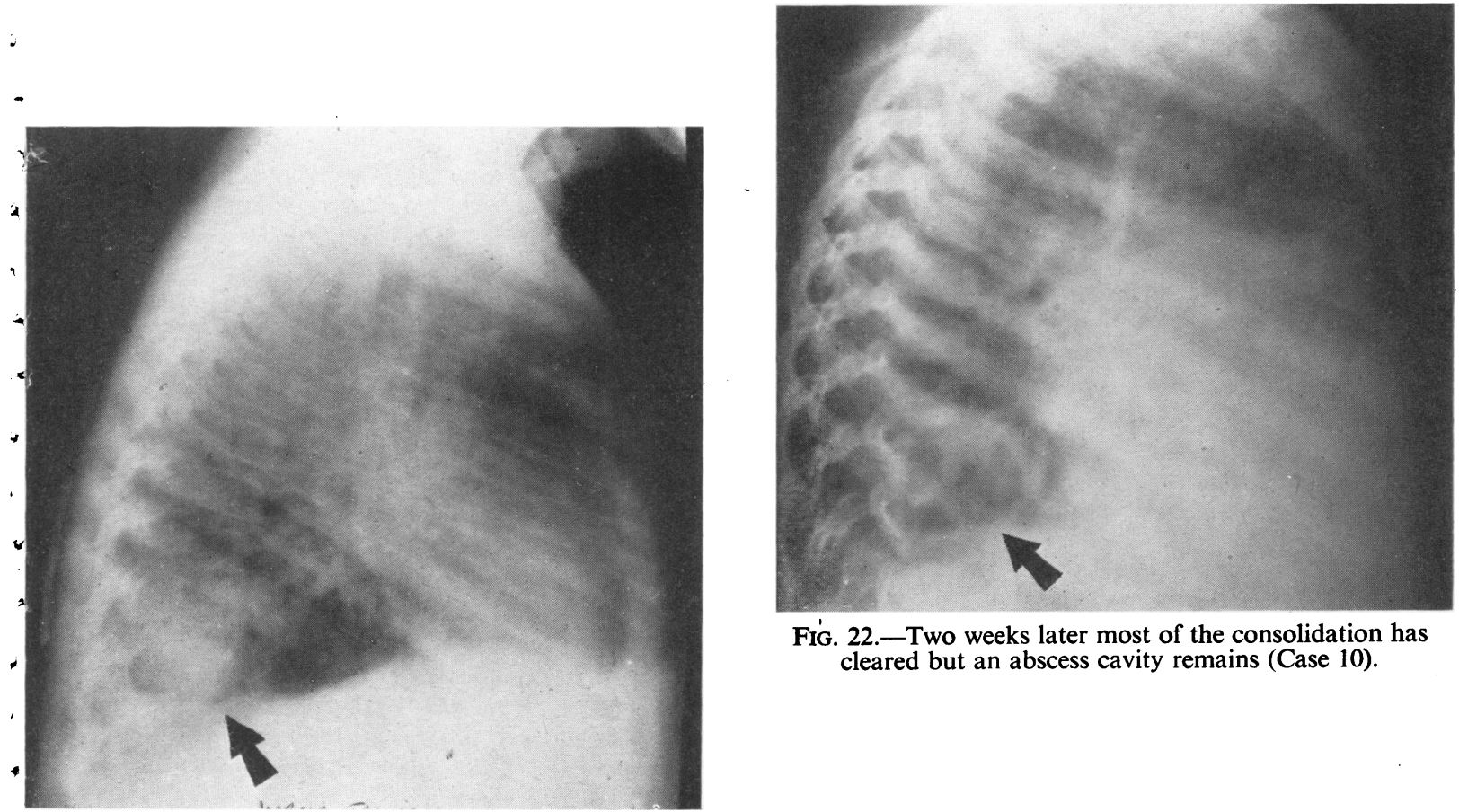

Fíg. 22.-Two weeks later most of the consolidation has cleared but an abscess cavity remains (Case 10).

FIg. 21.-Segmental pneumonia in the right lower lobe on admission (Case 10).

Fig. 23.-Seventh week. The abscess cavity has cleared (Case 10). 
coughing may produce some distension. The finding of bronchial epithelium in the lining of cysts is no argument against such an inflammatory origin, for it is well known that this epithelium tends to proliferate and grow over raw areas in much the same way that skin spreads over denuded areas on the surface of the body (Robb-Smith, 1936; Pryce, 1948). Regenerated bronchial epithelium may be poorly ciliated and columnar in type, but often squamous metaplasia occurs or the stretching of the cavity wall results in an unciliated cubical mucosa. This altered epithelium lacks that rhythmical sweeping motion of cilia which carries mucus up the normal bronchial tree, and as a result secretions tend to be retained in abscess cavities or bronchiectatic. sacs and predispose to further attacks of pneumonia.

Case 10. This case illustrates a lung abscess. A girl of $2 \frac{1}{2}$ years old suffered from chronic asthma, and was admitted during a severe attack accompanied by fever. Examination revealed signs of pneumonia at the right lung base (Fig. 21). She was given sulphonamides, penicillin, and antispasmodics, but remained febrile for one week and in status asthmaticus for three weeks. A radiograph after two weeks showed a thick-walled abscess cavity (Fig. 22) which cleared completely by the seventh week (Fig. 23).

A lung abscess in childhood may be secondary either to the aspiration of infected material or to the metastatic spread of infection from a septic focus elsewhere. Occasionally it occurs in the course of pneumonia, and in this case the responsible organism is the staphylococcus more often than the streptococcus, pneumococcus, or Friedländer's bacillus. All these organisms tend to cause a non-putrid lung abscess, and foul sputum mainly characterizes the lung abscess resulting from or complicated by anaerobic spirochaetes and fusiform bacilli.

Staphylococcal pulmonary infection accounts for less than $5 \%$ of pneumonias at all ages, but is relatively more common in early childhood, and in the pre-penicillin era it was accompanied by a considerable mortality (Heffron, 1939; Bullowa, 1937). It has been recognized that in addition to the fulminating type of staphylococcal pneumonia there is a relatively benign variety with a low fatality rate (Mac Keith, 1941 and Brock, 1945) have recently drawn attention again to the extraordinary frequency with which this type of pneumonia is accompanied by pulmonary cavitation. Staphylococcal pneumonia rarely occurs without some preceding illness, such as a cold or an attack of influenza. When developed, it is usually bronchopneumonic in type, and is accompanied by prostration, fever, and slight cyanosis. Blood culture may yield a growth of Staphylococcus aureus, and it is common to find the organism predominating in the sputum. The infection is overcome more slowly than other pneumonias, and abscess cavities often appear in the denser areas of consolidation. These cavities are at first thick-walled and contain purulent exudate but in a short time some become thin-walled ' soap bubble' cysts. The large cavities in staphylococcal pneumonia are reminiscent of pneumatocoeles, but the latter, unlike the former, are seldom accompanied by any recurrence of fever, increase in expectoration of sputum, deterioration in clinical condition, or raised mortality rate. Where the bacteriology was recorded in cases of pneumatocoeles recorded in the literature, the principal organism was usually either the staphylococcus, the pneumococcus, or the streptococcus. The pathology underlying a staphylococcal lung abscess and a pneumatocoele must be very similar, for in each the first appearance is often of a large fluid-filled cavity; later a segment of air is seen in it with a fluid level, and this in turn is succeeded by a thin-walled air cyst which eventually clears with little subsequent fibrosis. Brock (1945) has performed bronchograms on cases recovering from staphylococcal pneumonia and has shown that the bronchial tree is quite normal in some, while others have moderate but seldom severe bronchiectasis. Similar findings have been noted in some of my cases with pneumatocoele.

The pathological distinction between an abscess and a pneumatocoele is that the essence of the former is necrosis of lung tissue, whereas the latter is a cavity formed by the accumulation of air or exudate in a local area without much parenchymatous destruction. It does not seem to me feasible that the huge fluid-containing cavity of a staphylococcal abscess can be due to necrosis of tissue in any way commensurate with its radiological size, because resolution is so rapid and complete with little apparent residual fibrosis. It would appear that a staphylococcal lung abscess occupies an intermediate position between the air cyst that forms in the afebrile resolution phase of a pneumonia and the chronic cavity which results from the necrotizing process of an abscess due to anaerobic organisms. In clinical practice it may not be easy to establish a difference between an abscess and a pneumatocoele, but the point at issue here is that both are acquired lung cysts.

In adults there is a condition known as chronic or non-specific suppurative pneumonia (Logan and Nicholson, 1949) in which irregular consolidation occurs with a tendency to spread and form abscess cavities. No particular organism has been incriminated though many common ones occur in 


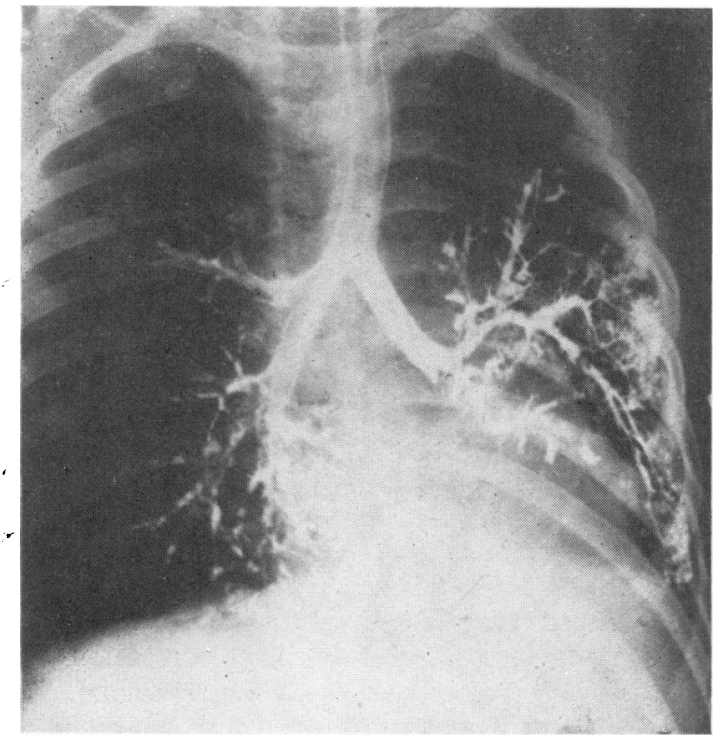

Fig. 24.-Well expanded left upper lobe one and a quarter years after a lower lobectomy and lingulectomy for bronchiectasis (Case 11).

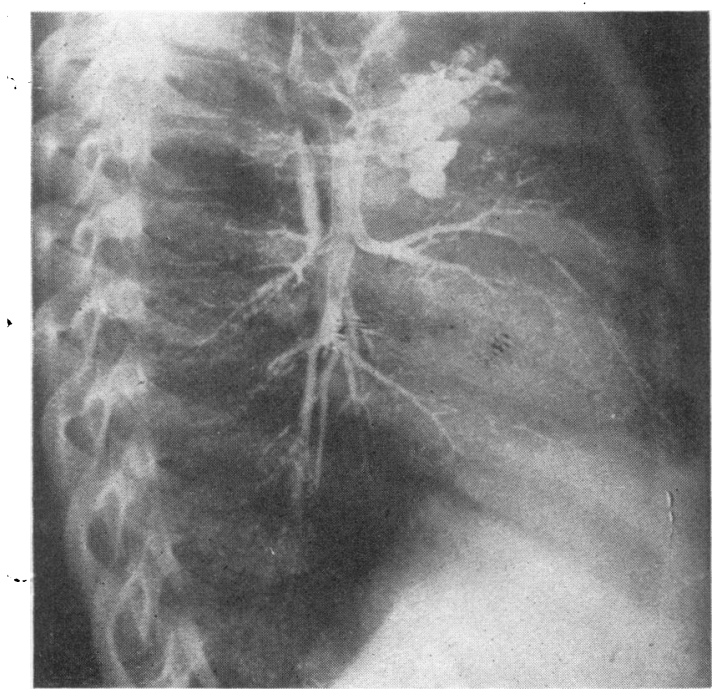

FIG. 26.-Saccular bronchiectasis following primary tuberculous infection one and a half years earlier(Case 12).

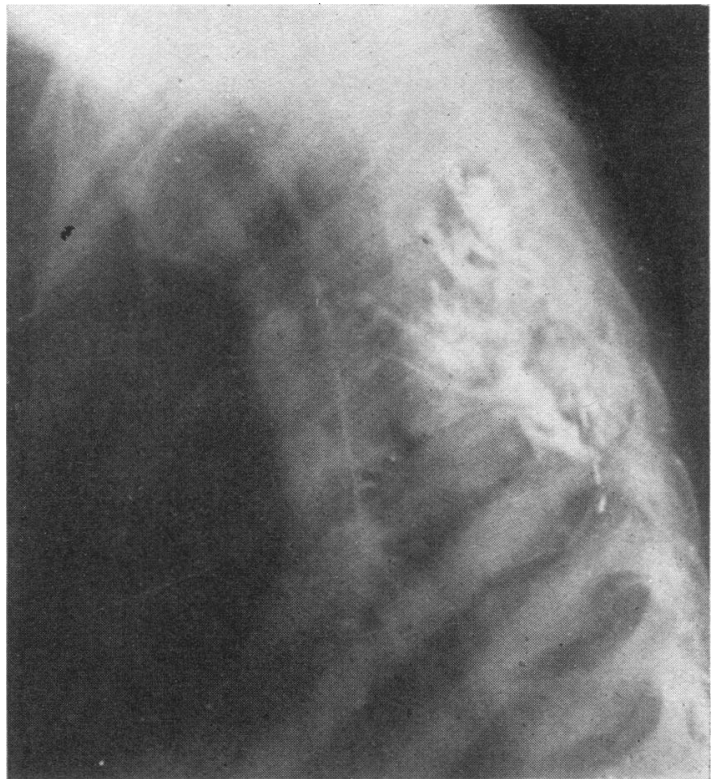

FIG. 25.-Two years later the left upper lobe is small and fibrotic containing shrunken dilated bronchi (Case 11).

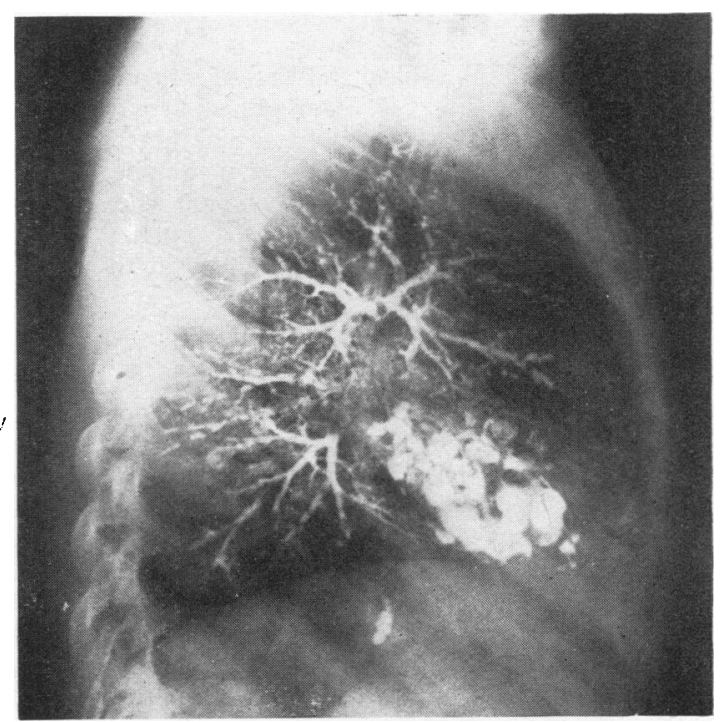

FIG. 27.-Cystic bronchiectasis in the right middle lobe two and a half years after pneumonia (Case 13). 
the sputum. The patient is febrile from time to time for many weeks, and the eventual prognosis is not good. It is possible that a similar condition occurs in children and produces lung cysts.

A cavity in the lung may arise not only from inflammatory necrosis of parenchyma but also by a process of infarction. Kessel (1930) has described several patients suffering from pneumonia who developed thrombosis of pulmonary and bronchial arteries together with necrosis and excavation of lung tissue. It is only possible to prove the occurrence of such a mechanism in the morbid specimen, but it might be suspected when pulmonary cavitation appears without fever in the resolution phase of pneumonia.

The conception that lung cysts can form by gross distension of small bronchial tubes by inflammatory exudate, and that it is unnecessary to invoke the pathology of a centrifugal necrosis of lung parenchyma which characterizes a lung abscess, is well illustrated by examining a series of cases beginning with mild bronchiectasis and working up to those with severe bronchial dilatation.

Case 11. This child had a left lobectomy and segmental resection for bronchiectasis when $5 \frac{1}{2}$ years old, but the remainder of the left upper lobe did not expand for four weeks after operation. Fig. 24 taken one and a quarter years later shows that some bronchiectasis had developed in a dependent bronchus, and Fig. 25, two years later, demonstrates a small fibrotic upper lobe with dilated bronchi.

Case 12. The child was $4 \frac{1}{2}$ years old and had chest symptoms since Mantoux conversion one and a half years previously. His radiograph showed saccular bronchiectasis in the apical and posterior segments of the right upper lobe (Fig. 26). During his primary infection glandular enlargement or endobronchial tuberculosis had probably obstructed the main bronchi to these segments.

Case 13. This patient had pneumonia when $2 \frac{1}{2}$ years old, and since then a productive cough. Fig. 27 demonstrates extensive cystic dilatation in the bronchi of the right middle lobe.

The connexion between bronchi and large air cysts is illustrated by the following case,

Case 14. This boy, aged 2 years, attended hospital with a cough and fever. A radiograph of his chest two months earlier was quite normal, but on admission he had at least four air cysts; two at the right base, which were partially filled with fluid, and two at the left base containing air only (Fig. 28). Bronchograms done four months later demonstrated that these cysts could be readily outlined (Figs. 29 and 30) and that many smaller cysts existed. Five months after admission there was little evidence of these cysts on a plain $x$-ray film. Four years later the bronchograms were repeated, and all that remained was varicose and saccular bronchiectasis in place of the former cysts (Figs. 31 and 32).

The radiographs of this child show a most instructive sequence of events. The initial radiograph of the chest was normal, but later valvular expansile cysts at both bases with inflammation and consolidation at the right base appeared. The cysts suggested temporary pneumatocoeles formed by emphysematous bullae or distended bronchioles. Viscous oil used for bronchography seldom enters such large cysts, because exudate or pressure occludes the bronchi leading to them. However, bronchograms done on this boy four months later showed numerous cysts affecting some of the secondary and tertiary axillary and basal bronchi of the lobes involved. The bronchograms four years later demonstrated one large sacculation of the axillary branch of the right posterior basal bronchus and varicose bronchiectasis in some other axillary and dependent branches in both lower lobes. The left lateral bronchogram revealed a very important finding, namely that the bronchial varicosity, which was all that remained of the former cysts, affected the centre segment of only the tertiary bronchi, the terminal parts being normal in calibre. The cysts had therefore not been emphysematous bullaeformed from alveoli, nor yet from bronchioles, but were on the contrary gross dilatations of small bronchi.

The cysts in this boy were not due to congenital malformation, for they were not present in his initial radiograph, and there is no justification for the assumption that empty developmental cavities were lying dormant until exposed by the air pressure

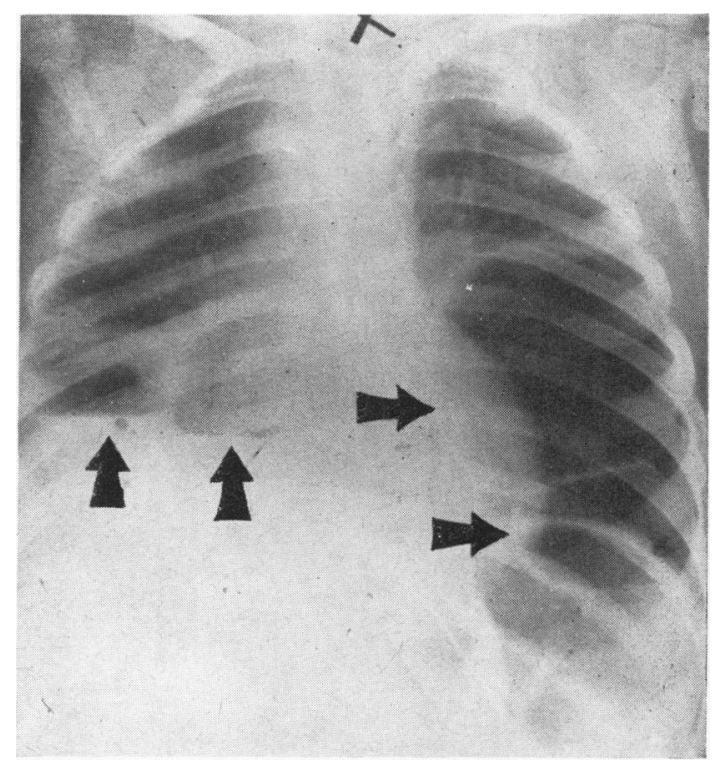

Fig. 28.-Boy aged 2 years. Two cysts at each base on admission (Case 14). 


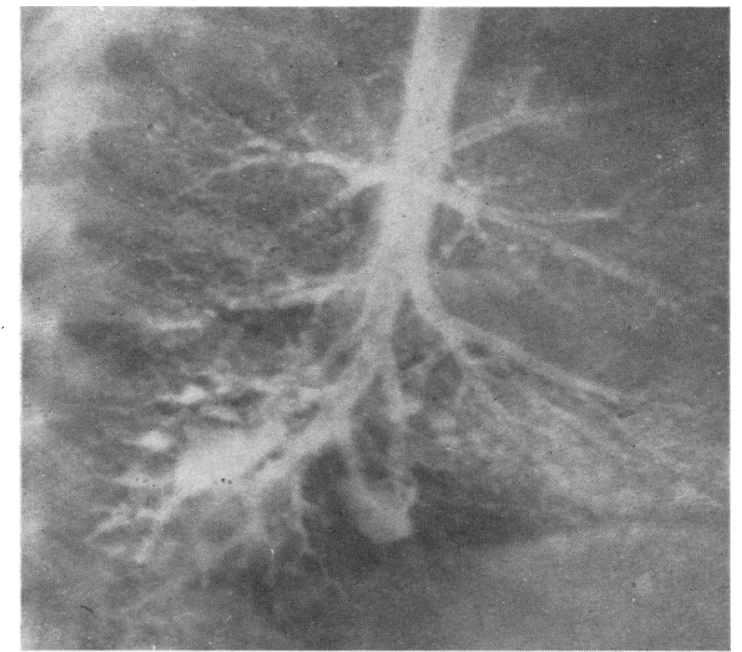

FIG. 29.-Right bronchogram four months later showing numerous cysts in the right lower lobe and two on axillary branches of a middle lobe bronchus (Case 14).

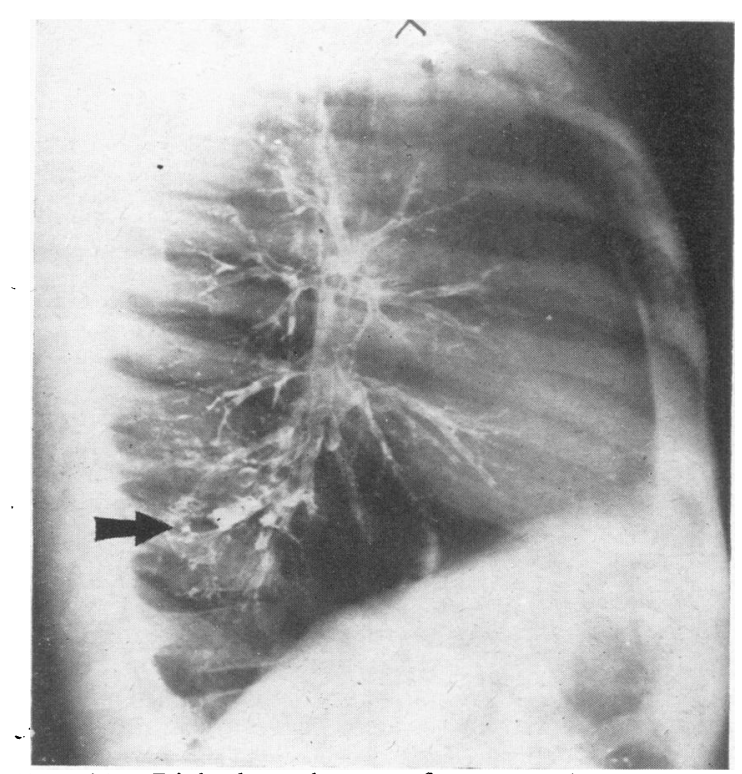

FIG. 31.-Right bronchogram four years later. Severe varicose and saccular bronchiectasis in the axillary branches of the lateral and posterior basal bronchi, possibly also of the cardiac bronchus (Case 14).

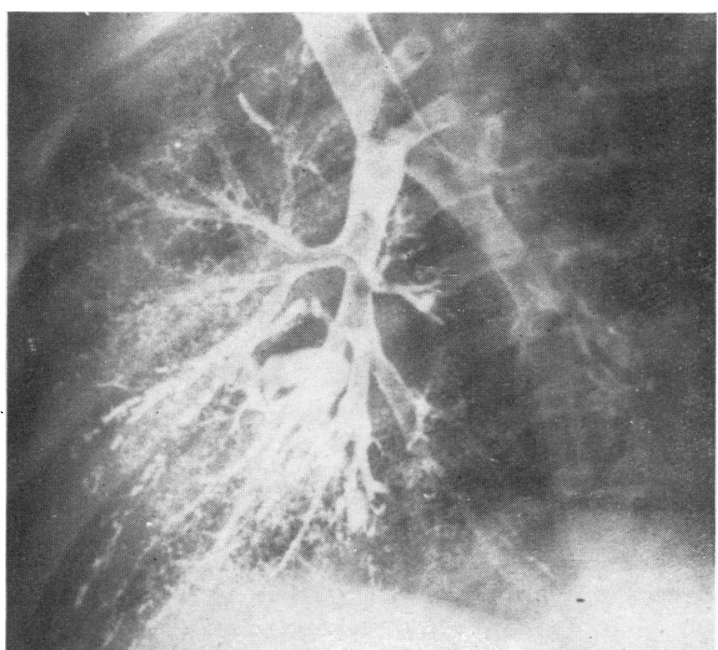

FIG. 30.-Left bronchogram four months later showing one large and several smaller cysts attached to the lower lobe bronchi (Case 14).

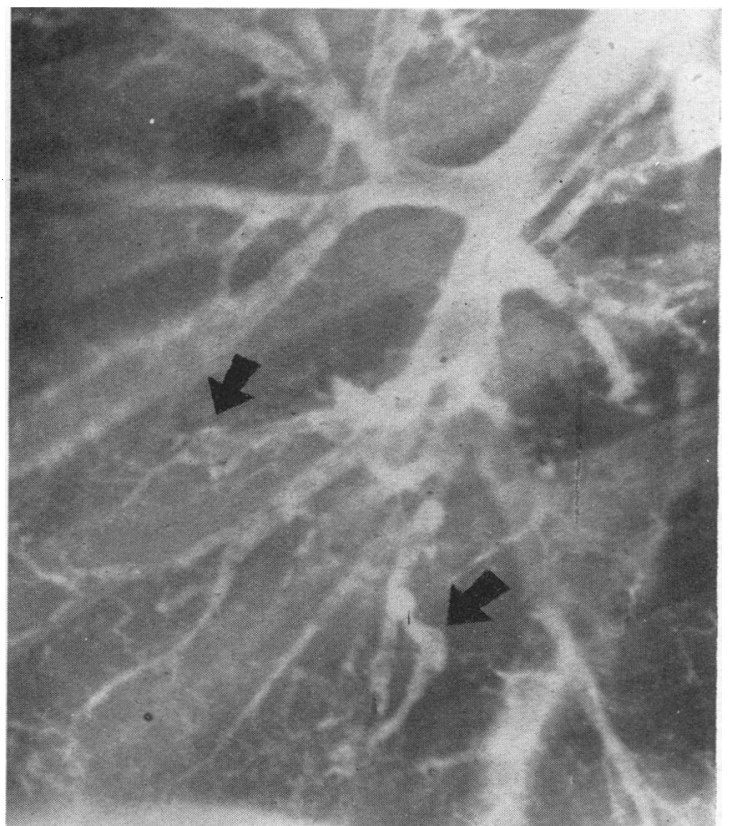

FIG. 32.-Left bronchogram four years later, showing marked varicosity of the axillary branch of the anterior basal bronchus and the same deformity of one of the smaller dependent branches of the middle and posterior 
changes or hydraulic effects consequent on bronchial inflammation. The mere fact that the cysts subsided into varicose bronchial dilatations suggests that they were produced through distension of bronchi by air or exudate under pressure. Sacculations of acquired bronchiectasis, due to an obstruction in a major bronchus, affect the weaker peripheral portions of the bronchial tree, such as the tertiary divisions, more often than the firmer walled primary or secondary branches. The fine terminal bronchi and bronchioles are seldom dilated because they are effectively plugged by thick exudate. Eloesser (1932) has shown that a valvular obstruction of a main bronchus which causes a high peripheral air pressure produces collapse of the parenchyma after an initial temporary phase of hyper-inflation, and that the weak peripheral bronchi then become dilated, even when there is no concomitant infection. This boy must have developed an infection and then valvular obstructions in some tertiary bronchi which caused segments of them to dilate enormously. When the stenoses cleared they deflated, but so far have not assumed a normal calibre.

In the past, it has been almost a tradition to believe that round cysts are congenital in origin, and bronchiectasis on the other hand is an acquired disease. The futility of such a generalization is well exemplified by the next case in which there were round cysts and a congenital anomaly.

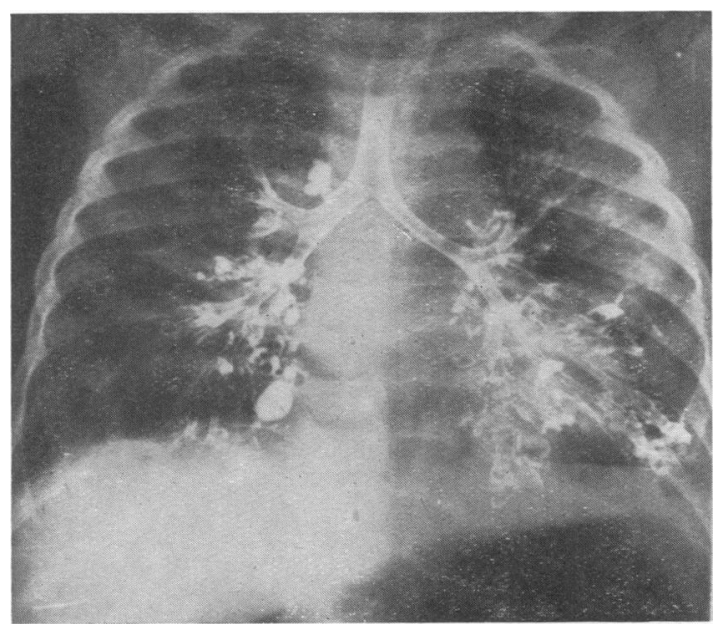

FIG. 33.-Aged $1 \frac{1}{2}$ years. Widespread varicose and saccular bronchiectasis in both lungs together with some round cysts, one of which springs from the right main bronchus in an abnormal position above the eparterial bronchus (Case 15).
Case 15. This girl of $1 \frac{1}{2}$ years had a productive cough since bronchitis at the age of 6 months. There was no history of pneumonia or of cyanotic attacks after birth. A bronchogram demonstrated varicose and saccular bronchiectasis in both lungs together with some round $\overline{\bar{F}}$ cysts, one of which sprang from the right main bronchi above the eparterial bronchus (Fig. 33).

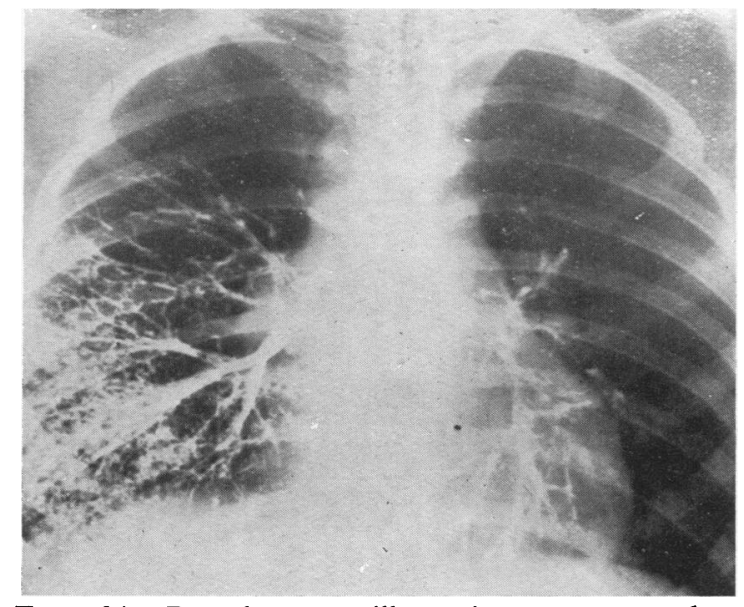

FIG. 34.-Bronchogram illustrating an anomalous bronchus of normal calibre arising from the trachea the level of the carina.

The early age at which symptoms began, together wh the widespread nature of her disease and the presence of a congenital anomaly, in this case suggested developmental origin of the bronchial dilatations. A staphylococcal bronchopneumonia could have caused $\bar{\partial}$ multiple cavities and bronchiectasis but this girl had no history of pneumonia. It is possible that multiple $\frac{}{\mathbb{D}}$ bronchial occlusions occurred in this child during or 2 following the initial bronchitis, and the secretions retained $\overrightarrow{\vec{\sigma}}$ caused the peripheral bronchi to dilate into bronchiectatic $\frac{0}{3}$ cavities or swell into cysts. It is not necessary to assume that she was born with a cyst attached to the right main bronchus, for this is as likely to have developed during? an infection in an anomalous bronchus of normal calibre as shown in Fig. 34.

Polycystic disease of the lungs may be bilateral or $\frac{0}{3}$ entirely confined to one side. Most children with multiple cysts have had several attacks of pneumonia, $ᄋ$ and it is impossible to ascertain whether the cysts occurred during the course of one of them oro originated earlier in a less severe pulmonary? infection. A spread of bronchiectasis is rarely $\frac{D}{2}$ observed in children followed up for many years, despite their chronic bronchitis, yet in the cases of $\mathrm{N}$ lung cysts described earlier, the number of cavities that can be seen varies from time to time,

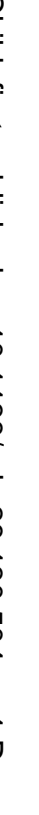




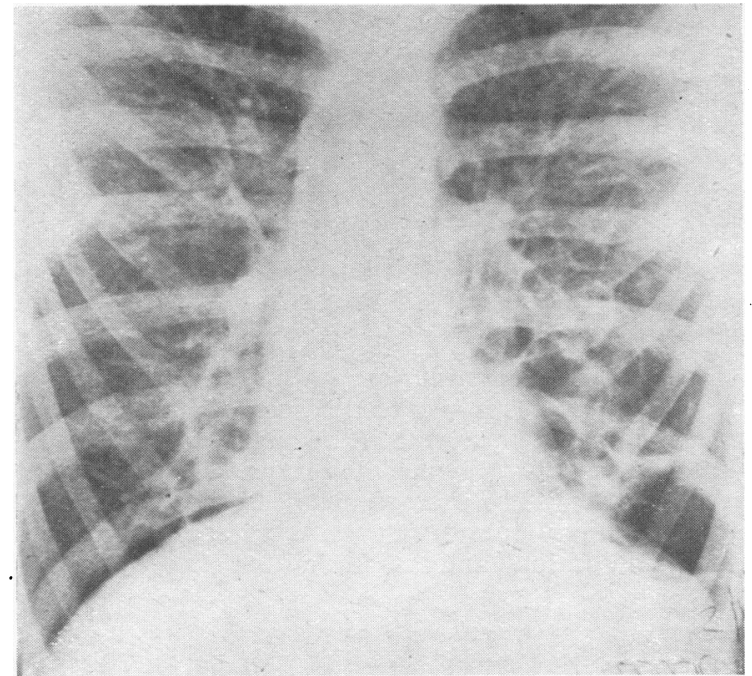

Fig. 35.-Multiple round cysts at both bases (Case 16).

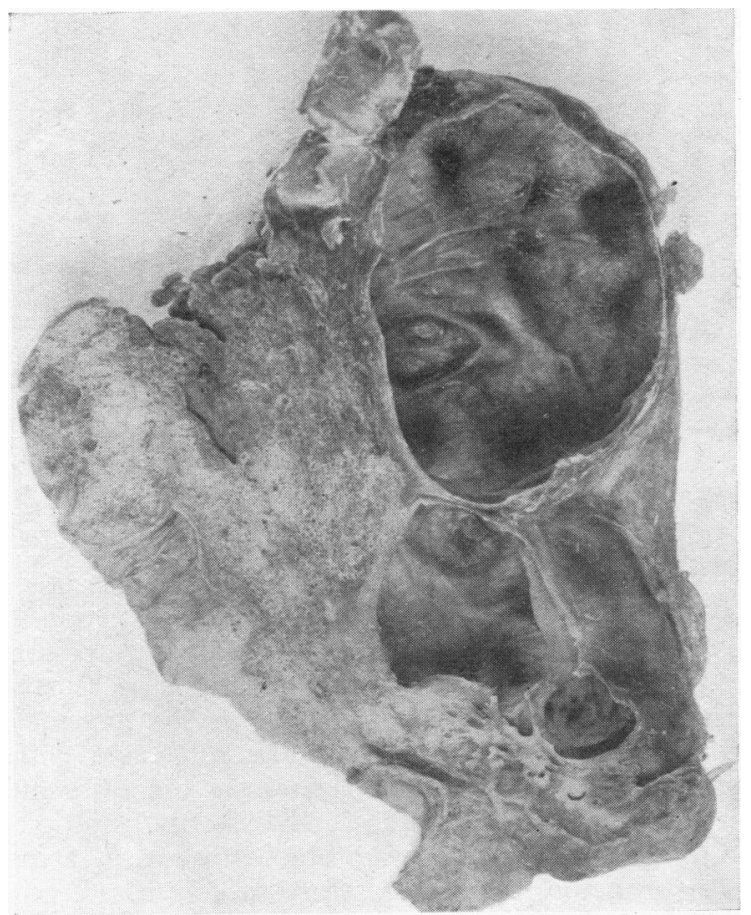

Fig. 36.-Operation specimen of the left lower lobe demonstrating the large size of some of the cysts (Case 16).

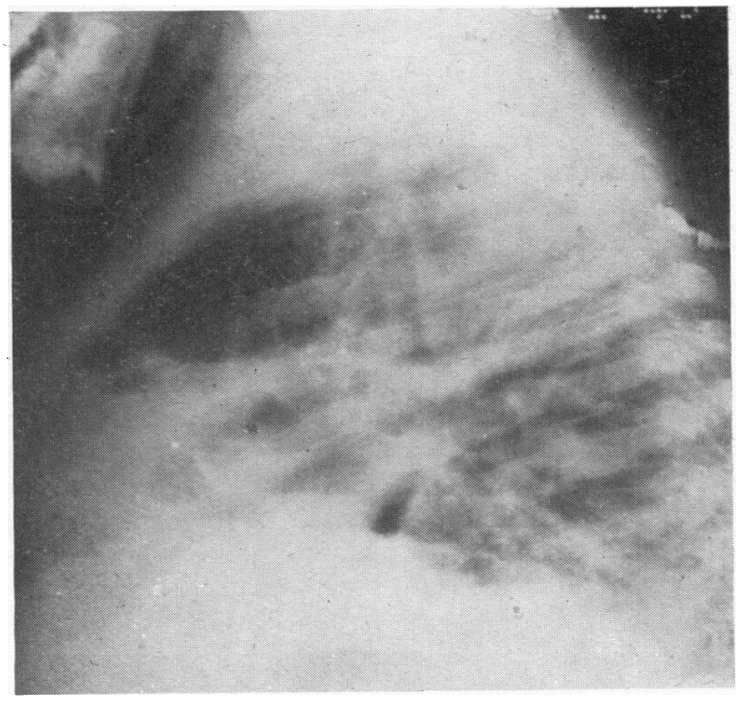

FIG. 37.-The whole left lung in this boy is riddled with cysts of all sizes. Right lung quite normal (Case 17). 
particularly after pneumonia. In the histology of bronchiectasis, the dilatations generally show almost complete destruction of the bronchial wall, and regeneration of mucosa over- replacement fibrous tissue. Though round cavities in the lung can result from abscess formation, cysts of the lung usually reveal less severe destruction of the tunica propria, and it is probable that they occur more often from distension of bronchi distal to an obstruction when this is unaccompanied by virulent infection in the retained secretions. Cases 16 and 17 are examples of polycystic lung disease, the former being bilateral, and the latter affecting the whole of the left lung, while the right lung was quite normal.

\section{Tuberculous Cavitation}

A cavity at the site of a primary focus from necrosis of parenchyma is a very rare phenomenon. Third stage tuberculosis or phthisis occurring before puberty is also rare, but it must be considered when a lung cavity is observed in a child with a positive Mantoux reaction.

Case 18. This case illustrates a phthisical cavity in a boy of 7 years. This boy complained of bronchitis for two months together with listlessness and nocturnal sweats. His only previous illness was measles at the age of 4 years. The radiograph of the chest showed a calcified primary complex at the right apex and tuberculous infiltration and cavitation at the left apex

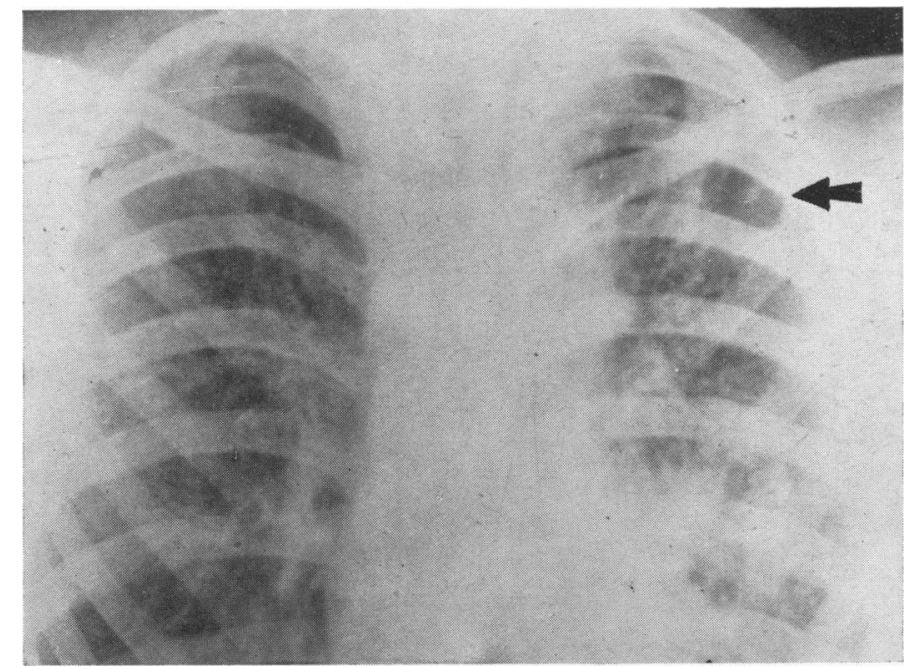

FIG. 39.-A calcified primary tuberculous lesion at the right apex with phthisical infiltration and cavitation at the left apex in a boy of 7 years (Case 18).

Case 16. This 11-year-old girl was admitted with a productive cough, gross clubbing of the fingers, and amyloid disease. At the ages of $2 \frac{1}{2}, 8$, and 9 years she had pneumonia but she complained of very few chest symptoms between these episodes. Her chest radiograph showed multiple cysts at the left base and a few at the right base (Fig. 35). The operation specimen of the left lower lobe demonstrates the size of some of the cysts (Fig. 36). A large bronchus can be seen to enter each of these cysts, and though they may be chronic smoothwalled abscess cavities, it is feasible for them to have developed by distension of the peripheral portions of the bronchi which connect with them.

Case 17. A boy of $3 \frac{1}{2}$ years had chest symptoms since pneumonia a year before. His chest radiograph showed that the whole left lung was cystic (Fig. 37). The whole right lung was normal as proved by bronchography. The operation specimen of the left lung is shown in Fig. 38, and it can be seen that the cysts are widely dilated bronchi.
(Fig. 39). Gastric lavage revealed numerous tubercle bacilli.

\section{Multiple Honeycomb Cysts}

Oswald and Parkinson (1949) are of the opinion that an understanding of the genesis of cystic disease of lungs has been clouded by the tendency of most writers to group together all cases with cysts, instead of studying separately the different forms, such as the simple lung cyst, the multiple honeycomb lung, the cysts which appear to arise from bronchial tissue, and those which arise from alveolar tissue. They have studied the honeycomb lung with its collection of thin-walled cysts distributed uniformly throughout both lungs and varying in size up to a maximum of $1 \mathrm{~cm}$. in diameter. They found that the clinical features of this group were distinctive: spontaneous pneumothorax which was often bilateral, and progressive 
right heart failure which led to death. In their 16 cases, six formed part of a general medical disorder, namely xanthomatosis, biliary cirrhosis, tuberose sclerosis, and diabetes insipidus. Their remaining 10 cases were of uncertain aetiology, and they assumed that these widespread cysts arose as developmental abnormalities, or were secondary to mechanical factors from acquired disease. In favour of the former they quoted a case of Rubin's (1947) which, apart from multiple simple cysts, had a patent ductus arteriosus, congenital aneurysms of the pulmonary arteries, and anomalous coronary arteries. Arnheim (1898) described a girl of $1 \frac{1}{2}$ years with honeycomb cysts of lung who also had congenital hypertrophy of the right side of the body.

The histology of the honeycomb lungs reported by Oswald and Parkinson (1949) has been studied by Cunningham and Parkinson (1950). They recorded that the cysts generally involved bronchioles, and were widespread throughout both lungs. In some, the lining consisted of simple cuboidal epithelium, and in others histiocytes or just collagenous material. Giant cells were found both in the lining and in the interstitial tissue of most cases, and the stroma about the cysts was composed of granulomatous material with a good deal of interstitial fibrosis. Plain muscle and elastica were difficult to find in the supporting structures, probably because they had been destroyed by inflammation. The lung parenchyma was greatly diminished in quantity; in some few normal alveoli remained. This was probably due to atrophy rather than to a failure of development, for the majority of cases were adults and symptoms had only been present for a few years. A short history of illness, usually a few weeks or months, also characterized the cases reported in early childhood by Sharkey (1892-3), Tooth (1897), Fletcher (1901), Bernstein (1905), and Collins (1933). The last two authors recorded finding large giant cells in the cyst walls though there was no evidence of tuberculosis. In Bernstein's case there was cholangitis without cirrhosis of liver, and in Fletcher's there was cholangitis associated with fibrosis and marked dilatation of the bile ducts. Honeycomb lungs in childhood have also been found in association with xanthomatosis and biliary cirrhosis by Rowland (1928) and Farber, Hampton, and Mueller (1942). Most of these authors noted that the cysts could not be emptied into the bronchial system, but on microscopy they appeared to be formed from bronchioles, and the alveoli and main bronchi were normal.

The actual mechanism of production of these bronchiolar or bronchoalveolar cysts which make up a honeycomb lung is unknown. Some may be due to a widespread obstruction of small bronchial tubes by inflammatory swelling of the mucosa, but in most cases reported the cysts have contained clear, glairy fluid rather than thick pus. Infiltration about the cysts with reticulo-endothelial and giant cells has suggested a reticulosis or xanthomatosis in some cases, and it has been suggested that the condition may be a manifestation of pulmonary sarcoidosis. As the cysts are formed from bronchioles, but cannot be emptied into the larger bronchi, some infiltration of the walls or firm exudate must be the cause of the bronchial occlusion. Though in two children honeycomb lungs were associated with indisputable congenital lesions, the majority of reported cases at all ages were notably free from pulmonary symptoms and ill-health until a short time before death, and it must therefore be concluded that honeycomb cysts of lung are acquired rather than developmental in origin.

\section{Traumatic Pulmonary Cysts}

Following traumatic rupture of lung parenchyma or a bronchus a haematoma is formed, and as the blood absorbs or drains away through the bronchial system, air replaces it and forms a gas-filled cavity in the lung. Rupture of a bronchus rarely occurs without tearing the parenchyma, except near the hilum, but a bronchus occasionally develops a valvular air leak due to perforation by a patch of ulcerative bronchitis (Allison, 1947). The next child is a good example of a traumatic lung cyst.

Case 19. This boy, aged 6 years, was pinned to the ground by a large metal frame, weighing about $1 \mathrm{cwt}$., which fell on the right side of his chest. He was released in a few seconds, but coughed up blood for the next half hour. A radiograph of his chest made on the same

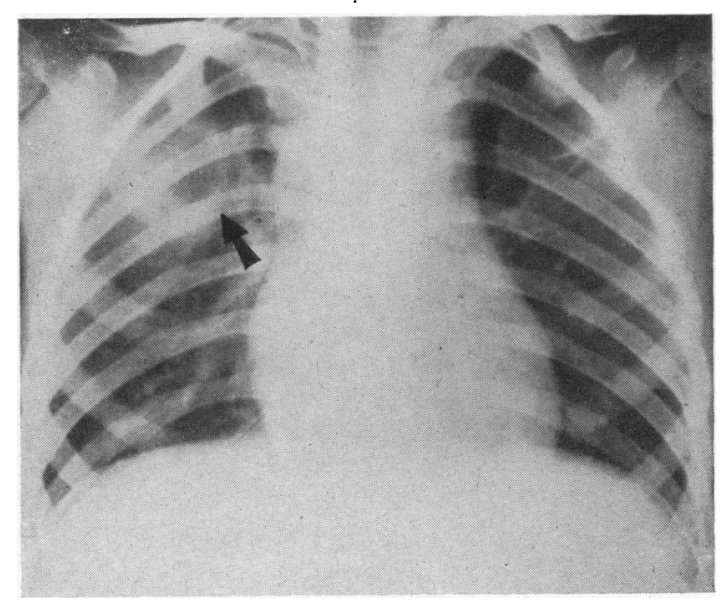

FIG. 40.-Traumatic air cyst of lung with surrounding haematoma three days after a blow over the right chest (Case 19). 
day revealed a mottled opacity in the right upper lobe. By the next day a circular translucency was present in the opacity. The chest film taken on the third day after the accident is reproduced in Fig. 40, and shows clearly the air cyst surrounded by lung consolidated by extravasated blood. He remained afebrile throughout, and the haematoma cleared by the ninth day. Five weeks after the accident the cyst could still be clearly seen (Fig. 41) but it had disappeared by the ninth week.

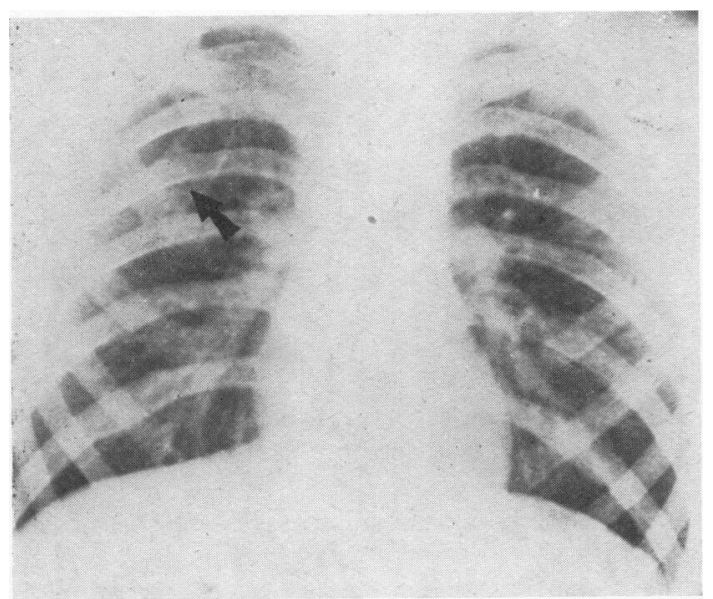

FIG. 41.-The air cyst in the right upper lobe is still present five weeks later (Case 19).

\section{Discussion}

Morbid anatomy attempts to deduce the processes of disease from a detailed study of many specimens at varying stages of evolution. Necropsy and operation material supply evidence of a static nature, and when cysts are found in the lungs the forces which produced them can only be surmised. An adequate knowledge of the vital changes in the body cannot be acquired from the limited field of cellular pathology, nor yet from bacteriology in which diseases are the predictable outcome of infection. An understanding of the dynamic processes which cause cysts to form in the lung can be gained more easily and accurately by clinical methods and the examination of serial chest radiographs of the same subject over a period of years. A list showing the age of the patients together with a careful description of the lung cyst in each would add little to present knowledge on the causation of cystic disease of the lungs, because the radiological appearances alter in response to changing mechanical forces and the powers of repair and destruction.

Congenital cystic disease of the lungs has a large literature, and many examples have been recorded in infancy. There can be no doubt that cysts in the lung are sometimes of developmental origin, but because such cysts can retain secretions and predispose to pulmonary infection, it is not necessary to assume that cavities in the lung after pneumonia have necessarily preceded it. A congenital aetiology is obvious when cysts are found in stillborn or newly delivered infants, but in any other age groups definite malformation must be observed which could not have arisen from an acquired pathology. After the first few days of life proof of a developmental origin can only be supplied from examination of the morbid specimen, and even this is unsatisfactory, for should a malformation not be found, it can be argued that all trace has been destroyed by postnatal infection. Collapsed or dormant cysts with evidence of congenital origin have rarely been observed in the lungs of children, but there is no doubt that cysts actually develop postnatally either because of infection or obstruction of bronchi. In this article cases have been cited to show the formation of cysts in lungs which, a short time before, were apparently quite normal. Such cysts not only appear, but enlarge, subside, or alter in number if observed over a long period of time, and these changes suggest that the cysts are the result of an acquired rather than a congenital mechanism.

Cavitation is usual in adult phthisis. Dormer, Friedlander, and Wiles (1945) have demonstrated by bronchography that there is always bronchial obstruction in such cases and very often bronchiectasis as well. The cavity formation is the result of tuberculous necrosis of the parenchyma but the bronchiectasis is due to bronchial obstruction and distension of the peripheral bronchi by inflammatory exudate. Emphysematous bullae are also frequent in a tuberculous lobe owing to a check valve mechanism in some of the finer bronchioles. Bronchography is rarely performed during an acute pyogenic inflammation of the lung, but there is reason to believe that the same events can occur though more rapidly. Inflammation of the bronchi produces swelling of the lining and exudation of mucus or mucopus. Occlusion of a bronchus predisposes to inflammatory destruction of its walls, and the retained infected secretions distend and dilate the peripheral tubes. Such dilatation may reach a marked degree in a week or two as has been demonstrated by the saccular cavities in experimental bronchiectasis, and those found in a person dying a few weeks after inhaling a foreign body. Occasionally the surrounding parenchyma becomes necrotic and a lung abscess results. A cavity in adult phthisis can distend into a balloon cyst because of a raised peripheral air pressure beyond a valvular bronchial obstruction, and as the same process may follow a pyogenic abscess in a child, it is plain that 
some air-containing cysts are formed in this way.

In bronchiectasis, a disease generally considered to be acquired, the bronchial dilatations are usually all of the same type; cylindrical, fusiform, varicose, or saccular. It does not seem logical that round cysts should be assumed to be congenital when in fact their appearance suggests a more severe degree of bronchial dilatation than is common in bronchiectasis. Round cysts can occur in bronchiectasis which is undoubtedly acquired. It has been suggested that such cases can be distinguished from congenital cystic disease of lungs by the chronic inflammatory changes in the bronchi of the former which are absent in the latter. The argument does not bear critical examination, for even in acquired bronchiectasis there is disagreement among authorities on the amount of chronic inflammatory tissue and bronchial destruction which is to be found. Lander and Davidson (1938) consider it is very slight, and Mallory (1947) and Robinson (1933) have recorded that in some cases it is quite minimal. Inflammatory changes usually subside when cellular and humoral resistance overcome the pathogenicity of the infective process. A recent abscess cavity is thick-walled and surrounded by consolidated alveoli, but within a few weeks the wall is generally thin and at least comparable in thickness to that of pulmonary air cysts which have in the past been assumed to be congenital. The two most important causes of bronchiectasis and lung abscess are bronchial obstruction and infection. Bronchiectasis is predominantly a disease which occurs in childhood, and almost half of the cases of cystic disease of lungs collected in Schenck's review of the literature (1937) were under 15 years of age. Pulmonary infection is common in both the young and the old, but bronchial obstruction affects children more than adults because their bronchi are narrower and more easily occluded by a swollen mucosa, mucus plugs, or the external pressure of enlarged lymph nodes.

Bronchopneumonia principally involves the bronchi and surrounding tissue, and when the infection is staphylococcal, multiple abscess cavities sometimes result. In lobar pneumonia there is an extensive outpouring of inflammatory exudate which consolidates the parenchyma but the bronchi are much less affected. Valvular obstruction of the finer bronchi and bronchioles during the resolution of pneumonia leads to the rapid formation of pneumatocoeles either on the surface of the lobe or buried within its substance. These air cysts often contain inflammatory exudate, but as the infective process is on the wane when they occur there is little necrosis. With the absorption or expulsion of the material that occluded the finer tubes the pneumatocoeles usually disappear completely, but sometimes they are perpetuated by organic post-inflammatory bronchial stenosis.

It is impossible to tell radiologically whether cysts in the lung have started from a necrotic destruction of parenchyma by a lung abscess, or are due to the distension of small bronchi, bronchioles, or a collection of alveoli. Histological examination of the widened tubes in bronchiectasis generally shows a marked degree of destruction of the walls yet the eventual dilatations are elongated and in the general line of the former bronchi. A necrotic destruction of parenchyma, on the other hand, tends to spread centrifugally from some central focus, and after liquefaction and removal of the contents the resulting cavity is spherical. Bronchial epithelium relines the walls after the acute phase in bronchiectasis or a lung abscess, but the finding of other bronchial elements, such as muscle and elastic tissue, in the lining of some large cysts or in the walls of some bronchiectatic cavities suggests that ulcerative destruction of tissue was not a necessary stage in the formation of either.

The gross distension of a bronchial cyst, whether congenital or acquired, is likely to cause atrophy of the tunica propria, seromucous glands, cartilage, and surrounding alveoli. An intact bronchial stroma or fragments of it in the wall of a cyst has been taken as proof of a congenital aetiology, but this is unreliable for it has been demonstrated by the cases quoted here that cysts can develop and enlarge with practically no accompanying systemic reaction. The bronchi, bronchioles, or alveoli are distended into cavities by air pressure or exudate with little or no inflammatory destruction of tissue. The rapid dilatation of bronchi would cause distortion and scattering of the cartilage muscle and elastic tissue in their walls, and so finding clumps of these structures should not indicate a failure of normal formation originally. A congenital cyst of any structure in the foetus is invariably due to an impediment in the normal flow of body fluids. The dilated bronchial cavities observed in foetal lungs or portions of aberrant lung tissue are associated with bronchial obstruction, and it therefore seems reasonable to expect a similar obstruction in postnatal life to have the same effect. Congenital cysts have been considered a result of the failure of formation of alveoli and small bronchial tubes, but their absence in a morbid specimen can equally be accounted for by atrophy through compression by an enlarging cyst. Absence of carbon pigmentation in the parenchyma of some cases with cystic disease of the lungs is not conclusive of prenatal development, but implies that the cyst formed in 
early infancy and impeded the respiratory function of the parts lacking the pigment.

Eloesser (1932) has made an extensive study of bronchial stenosis and noted that the result of stenosis depends on its site along the bronchial tree. A diffuse limitation of expiration, as found in asthma or valvular tracheal obstruction, produces a bilateral increase in lung volume. A valvular constriction of a bronchus to a lobe leads at first to over-expansion of the related parenchyma, but, as the obstruction to the expiration of air becomes more marked, alveolar collapse and dilatation of distal bronchi result. A similar valvular obstruction at bronchiolar level causes the alveoli to dilate and local emphysema. The latter is curiously localized, for some alveoli are hyperinflated while others are collapsed. Tannenberg and Pinner (1942), in their experimental work on rabbits, have shown that after complete bronchial obstruction pulmonary collapse occurs within about four hours, and in the absence of infection the distal bronchi are constricted. With infection beyond a block the distal bronchi rapidly become dilated with secretions, and may come to resemble a collection of sacs within a few days or weeks. They also recorded that alterations in intrapleural pressure did not affect the eventual formation of bronchial cavities.

Pulmonary collapse is common in childhood, yet is rarely complicated by the development of a lung cyst. Most pulmonary collapses are due to bronchial occlusion by mucus plugs created during bronchial inflammation, produced in asthmatic allergy or aspirated from the upper respiratory tract. When the collapse occurs there is usually a rise of body temperature for a day or two indicating some systemic infection. The rarity of cyst formation is not due to the small amount of intrabronchial material and its rapid clearance, because widespread rhonchi may persist for many days and the duration of a pulmonary collapse is measured in weeks. It is probable that mucus plugs, when they begin to loosen, are rapidly expelled or are softened to such an extent that they do not function well as check valves. For the production of a valvular mechanism, an organic stenosis formed by congested folds of mucosa or inflammatory constriction of the bronchial lumen may be necessary. Air is thought to permeate from aerated lung segments into collapsed ones through the interalveolar pores of Kohn, and aid in the expulsion of mucus plugs from small bronchi by the blast of air on coughing. It is possible that cysts occur during pneumonia because the interalveolar pores are blocked by exudate and do not relieve the air pressure behind a valvular obstruction.

Some children present with cysts in the chest, though they have no history of a severe pulmonary infection. It is not necessary to conclude that the cysts were formed by some mechanism in which inflammation was not a part, because in these days children are readily treated with antibiotics and chemotherapeutic drugs, often before the true nature of the complaint has been diagnosed. It is well known that fever and toxaemia in pneumonia rapidly respond to these drugs although the process of resolution still takes many days. The absence of a history of pneumonia cannot therefore be taken as evidence that the cysts in the child's lung were not the result of this pathology. It is possible, however, for cysts to form without any inflammation or obvious infection. An air-containing lung cavity can form after traumatic rupture of lung. In the adult asthma sufferer emphysematous bullae are common, and these occasionally occur in children and are seen as cyst-like translucencies on radiography. Over-distension of alveoli in an asthmatic person may also lead to cyst-like pockets of air in the interstitial planes through rupture of alveolar walls. Fibrosis of lung following past pyogenic or tuberculous inflammation is a cause of organic valvular bronchial stenosis and pulmonary cysts.

Allison (1947) has described large air cysts in adults, some of which were due to organic valvular stenosis and others to a small bronchial leak caused by a patch of ulcerative bronchitis. All his patients suffered from a cough, but few had had acute pulmonary infection, and the cysts showed a striking resemblance to the thin-walled cavities which occur in children. He noted that although the cysts looked like huge emphysematous bullae some of them were partly lined by cuboidal epithelium, and he made the interesting observation at operation on his cases that air entered a cavity with each forced expiration rather than during inspiration. If adults with relatively wide bronchi can develop stenosis and lung cysts it seems reasonable to suppose that children can do so with even greater facility because of the narrowness of the bronchi and the common history of a chronic cough over many months each year.

Material evidence of a congenital aetiology of lung cysts is rarely obtained, and it does not seem reasonable consistently to conclude that this has been destroyed by subsequent pulmonary inflammation. The observation in serial radiographs that cysts of lung can appear, enlarge, disappear, recur, or alter in number strongly supports the view that these pulmonary cavities are the result of an acquired pathology.

\section{Summary}

Cysts in the child's lung may be congenital or acquired. Very few have been recorded in stillborn 
or newborn infants, but it has been generally assumed that most cysts are due to congenital malformation.

A number of lung cyst cases, observed over many years, are reviewed and the aetiology of the cysts discussed.

The conclusion is reached that most lung cysts are acquired as a result of bronchial inflammation and obstruction, and that very few are truly congenital in origin.

I wish to thank Dr. B. E. Schlesinger and Dr. R. E. Bonham Carter for their permission to publish this paper. I am grateful to Dr. C. J. Hodson, of the Radiological Department, University College Hospital, for the loan of Case 19; to Dr. W. G. Wyllie, of The Hospital for Sick Children, Great Ormond Street, for allowing me to use Cases 4 and 7; to Mr. Denis Browne for Case 2. I should also like to thank Dr. C. E. Field and all those who by their advice and criticism have helped to produce this paper, and Miss E. Marshall for her secretarial assistance.

\section{REFERENCES}

Adams, R., and Churchill, E. D. (1937). J. thorac. Surg., 7, 206.

Allison, P. R. (1947a). Thorax, 2, 169, 176.

Almklov, J. R., and Hatoff, A. (1946). Amer. J. Dis. Child., 72, 521.

Andrews, C. T. (1949). Brit. med. J., 2, 1269.

Arnell, S. (1927). Acta radiol., Stockh., 8, 252.

Arnheim, G. (1898). Virchows Arch., 154, 300.

Balzer, F., and Grandhomme, A. (1886). Rev. mens. Mal. Enf., 4, 485.

Barlow, T. (1880).' Brit. med. J., 1, 14.

Bartholinus (1687). Quoted by Cole, D. B., and Nalls, W. L. (1938). J. Lab. clin. Med., 24, 147.

Benjamin, B., and Childe, A. E. (1939). J. Pediat., 15, 621 .

Bernstein, J. M. (1905). Trans. path. Soc. Lond., 56, 330.

Biermer, A. (1860). Virchows Arch., 19, 94, 241.

Brock, R. C. (1945). Guy's Hosp. Rep., 94, 115.

Brown, R. K., and Robbins, L. L. (1944). J. thorac. Surg., 13, 84.

Bullowa, J. G. M. (1937). 'The Management of the Pneumonias,' p. 411. New York.

Caffey, J. (1940). Amer. J. Dis. Child., 60, 586.

Carlson, H. A. (1943). J. thorac. Surg., 12, 376.

Cockayne, E. A. (1938). Quart. J. Med., N.S.7, 479.

Collins, D. H. (1933). J. Path. Bact., 37, 123.

Couvelaire, A. (1904). Rev. mens. Mal. Enf., 22, 60.

Cunningham, G. J., and Parkinson, T. (1950). Thorax, 5,43 .

Dormer, B. A., Friedlander, J., and Wiles, F. J. (1945). Amer. Rev. Tuberc., 51, 455, 519.

Doub, H. P. (1928). Amer. J. Roentgenol., 20, 6.

Dubreuil, G., Lacoste, A., and Raymond, R. (1936). Bull. Histol. Tech. Micr., 13, 235.

Eloesser, L. (1932). J. thorac. Surg., 1, 270.

Farber, S., Hampton, A. O., and Mueller, H. L. (1942). New Engl. J. Med., 226, 392.

Fishberg, M. (1917). Arch. intern. Med., 20, 739.

Fletcher, H. M. (1901). Trans. path. Soc. Lond., 52, 193.

Fontanus (1638). Quoted by Cole, D. B., and Nalls, W. L. (1938). J. Lab. clin. Med., 24, 147.

Francke, W. (1894). Dtsch. Arch. klin. Med., 52, 125.
Friedreich, N. (1857). Virchows Arch., 11, 466.

Gold, E. (1921). Beitr. path. Anat., 68, 278.

Grawitz, P. (1880). Virchows Arch., 82, 217.

Hammar, J. A. (1904). Beitr. path. Anat., 36, 518.

Heffron, R. (1939). ' Pneumonia,' p. 9. New York.

Heller, A. (1885). Dtsch. Arch. klin. Med., 36, 189.

Hueter, C. (1914). Beitr. path. Anat., 59, 520.

Hondo, T. (1904). Zbl. allg. Path. path. Anat., 15, 129.

Humphry, L. (1885). J. Anat., Lond., 19, 345.

Kartagener, M. (1933). Beitr. Klin. Tuberk., 83, 489.

Kessel, L. (1930). Arch. intern. Med., 45, 401.

Klebs, E. (1889). 'Die allgemeine Pathologie,' Vol. 2 p. 354 . Jena.

Koontz, A. R. (1925). Bull. Johns Hopk. Hosp., 37, 340.

Laennec, R. (1821). 'A Treatise on the Diseases of the Chest,' trans. J. Forbes, p. 108 . London.

Lander, F. P. L., and Davidson, M. (1938). Brit. J. Radiol., 11, 65.

Laurell, H. (1929). Acta radiol., Stockh., 10, 72.

Linser, P. (1899). Virchows Arch., 157, 281. (1900). Arb. anat. Inst. Wiesbaden, 13, 309.

Lister, G. (1941). Amer. J. Dis. Child., 62, 613.

Logan, A., and Nicholson, H. (1949). Thorax, 4, 125.

Löhlein, M. (1908). Verh. Dtsch. path. Ges., 12, 111.

López Areal, L. (1944). Rev. clinica esp., 14, 378.

Mac Keith, R. (1941). Lancet, 2, 354.

McNeil, C., Macgregor, A. R., and Alexander, W. A. (1929). Archives of Disease in Childhood, 4, 111.

Mallory, T. B. (1947). New Engl. J. Med., 237, 795.

Meyer, H. (1859). Virchows Arch., 16, 78.

Muus, N. (1904). Ibid., 176, 180.

Olsen, A. M. (1943). Amer. Rev. Tuberc., 47, 435.

Oswald, N., and Parkinson, T. (1949). Quart. J. Med., 18,1 .

Pappenheimer, A. M. (1912). Proc. N Y. path. Soc., 12, 193 .

Peirce, C. B., and Dirkse, P. R. (1937). Radiology, 28,651 .

Pryce, D. M. (1948). J. Path. Bact., 60, 259.

- -, Sellors, T. H., and Blair, L. G. (1947). Brit. J. Surg., 35, 18 .

Robb-Smith, A. H. T. (1936). Beitr. path. Anat., 97, 481.

Robinson, W. L. (1933). Brit. J. Surg., 21, 302.

Rowland, R. S. (1928). Arch. intern. Med., 42, 611.

Rubin, E. H. (1947). ' Diseases of the Chest,' p. 432. Philadelphia.

Ruge, C. (1878). Berl. klin. Wschr., 15, 401.

Sauerbruch, F. (1934). Arch. klin. Chir., 180, 312.

Schenck, S. G. (1937). Arch. intern. Med., 60, 1.

Seltsam, A. (1905). Virchows Arch., 180, 549.

Sharkey, S. J. (1892-3). St. Thom. Hosp. Rep., 22, 33.

Smith, S. (1925). Brit. med. J., 1, 1005.

Snow, W., and Cassasa, C. S. B. (1937). Amer. J. Roentgenol., 37, 217.

Stoerk, O. (1897). Wien klin. Wschr., 10, 25.

Tannenberg, J., and Pinner, M. (1942). J. thorac. Surg., 11, 571 .

Tooth, H. H. (1897). Trans. path. Soc. Lond., 48, 30.

Torgersen, J. (1946). Acta med. scand., 126, 319.

Virchow, R. (1862). "Gesammelte Abhandlungen zur Wissenschaftlichen Medicin,' Ed. 2, p. 982. Frankfurt.

Vogel, R. (1899). Virchowis Arch., 155, 235.

Wolman, I. J. (1930). Bull. Aver clin. Lab., 2, No. 12. p. 49.

Zahn, F. W. (1896). Virchows Arch., 143, 170.

Zipkin, R. (1907). Ibid., 187, 244. 